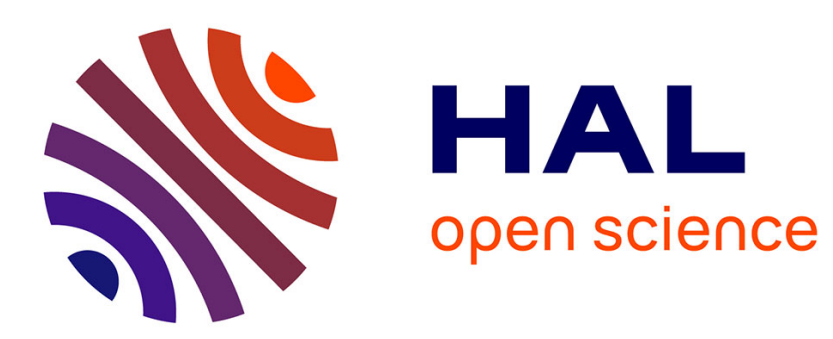

\title{
Control systems for direct steam generation in linear concentrating solar power plants
}

\author{
Antoine Aurousseau, Valery Vuillerme, Jean-Jacques Bézian
}

\section{To cite this version:}

Antoine Aurousseau, Valery Vuillerme, Jean-Jacques Bézian. Control systems for direct steam generation in linear concentrating solar power plants: a review. Renewable and Sustainable Energy Reviews, 2016, 56, p. 611-630. 10.1016/j.rser.2015.11.083 . hal-01609110

\section{HAL Id: hal-01609110 https://hal.science/hal-01609110}

Submitted on 7 Nov 2018

HAL is a multi-disciplinary open access archive for the deposit and dissemination of scientific research documents, whether they are published or not. The documents may come from teaching and research institutions in France or abroad, or from public or private research centers.
L'archive ouverte pluridisciplinaire HAL, est destinée au dépôt et à la diffusion de documents scientifiques de niveau recherche, publiés ou non, émanant des établissements d'enseignement et de recherche français ou étrangers, des laboratoires publics ou privés. 


\title{
Control systems for direct steam generation in linear concentrating solar power plants - A review
}

\author{
Antoine Aurousseau ${ }^{\mathrm{a}, \mathrm{b}, *}$, Valéry Vuillerme ${ }^{\mathrm{a}}$, Jean-Jacques Bezian ${ }^{\mathrm{b}}$ \\ a Univ. Grenoble Alpes, INES, CEA, LITEN, Laboratoire des Systèmes Solaires Haute Température, F-33375 Le Bourget du Lac, France \\ ${ }^{\mathrm{b}}$ Université de Toulouse, Mines Albi, CNRS, Centre RAPSODEE, France
}

\section{A B S T R A C T}

Concentrating Solar Power (CSP) plants generate renewable electricity using the conversion of solar direct normal irradiation into thermal energy, then into mechanical work and electricity through the use of a thermodynamic cycle. Among the several available technologies, Direct Steam Generation (DSG), in which steam is generated directly in the absorber tubes of the solar field, and then directly fed to the turbine or thermal storage, holds interesting advantages. However, the steam generation system shows a difficult dynamic behavior which constitutes a challenge for the control system design. It is mainly due to the conjunction of the natural transient condition of solar irradiation and the presence of two phase flow in the absorber tubes. This paper reviews the control methods of the DSG systems used in linefocus CSP. The control systems are either proposed in literature, or actually applied in currently running plants or prototypes, although an extensive description is difficult to obtain in the case of the latter. The control systems are classified according to which DSG operation mode they refer to.

Keywords:

Concentrating Solar Power

Line-focus

Direct steam generation

Control systems

\section{Contents}

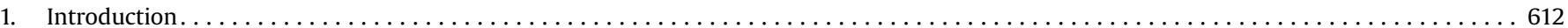

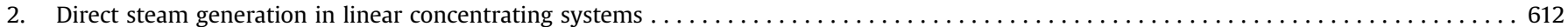

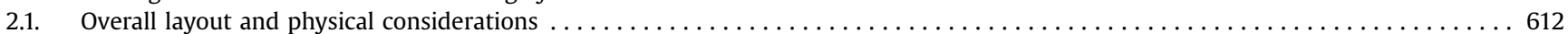

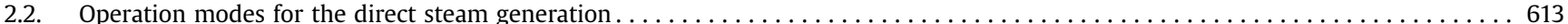

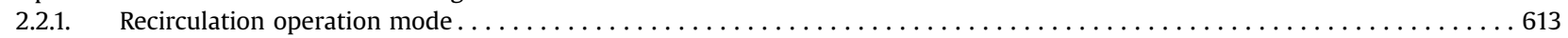

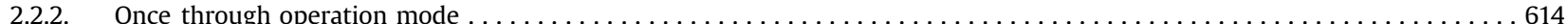

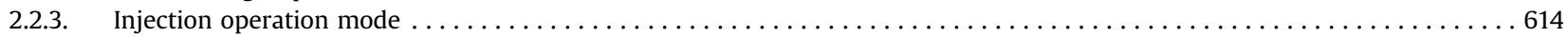

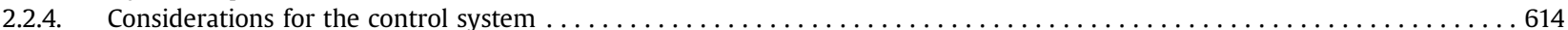

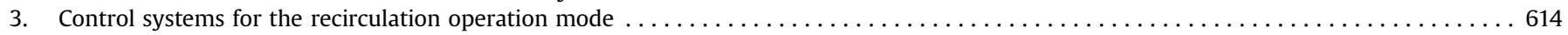

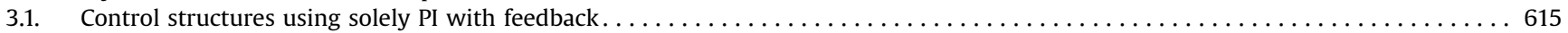

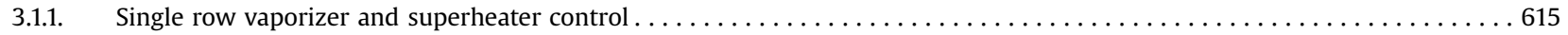

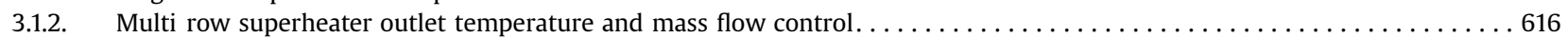

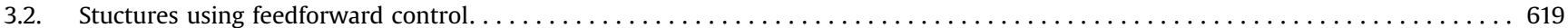

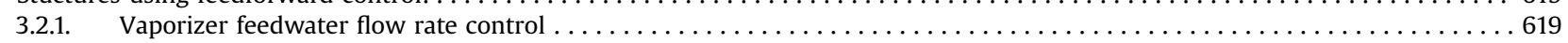

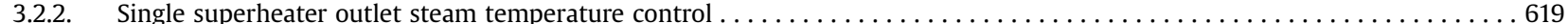

3.3. Structures using "predictive" control: Separator level control with dead time compensation ................... 620

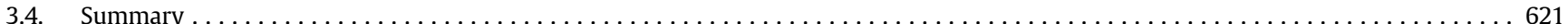

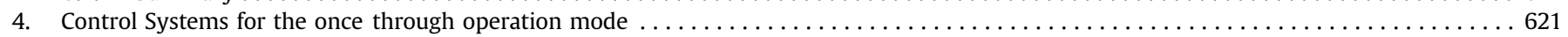

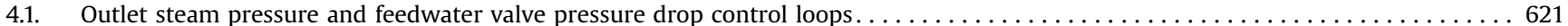

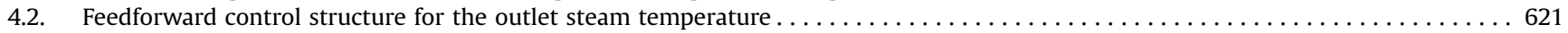

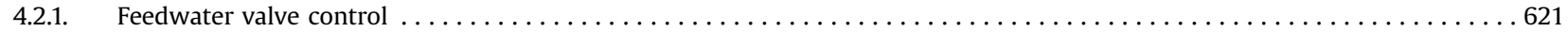

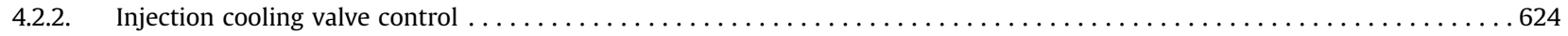

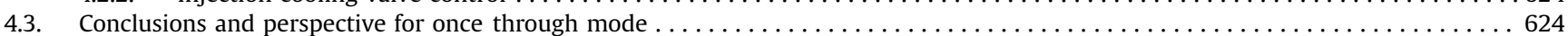




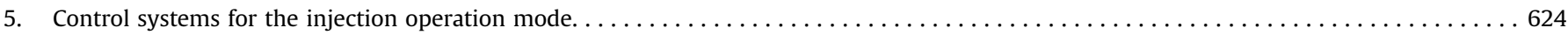

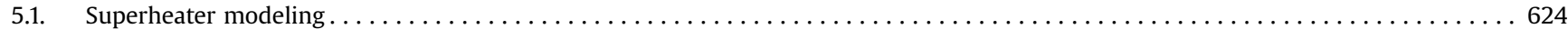

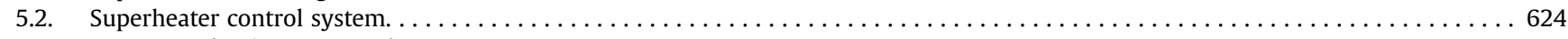

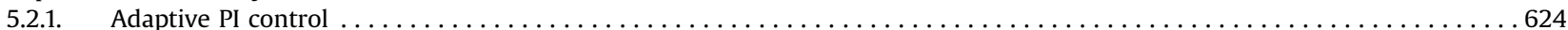

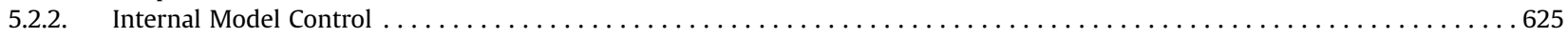

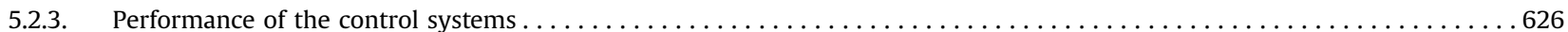

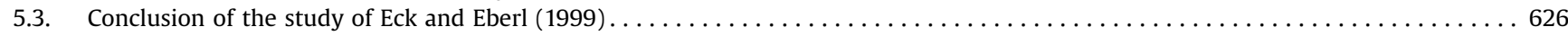

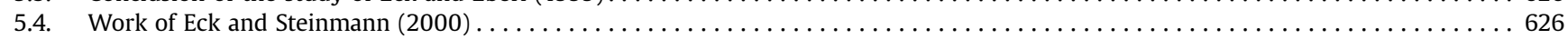

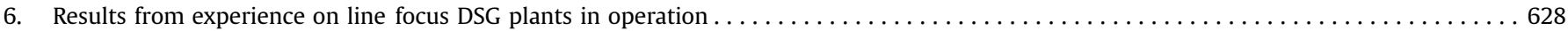

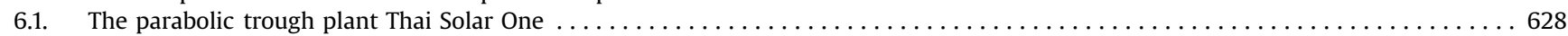

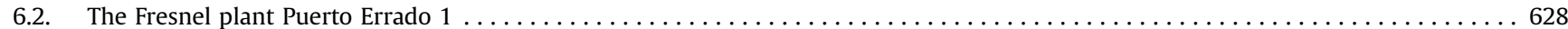

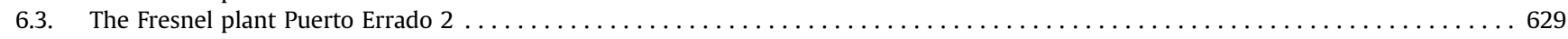

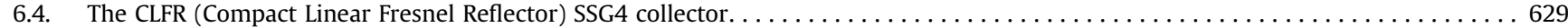

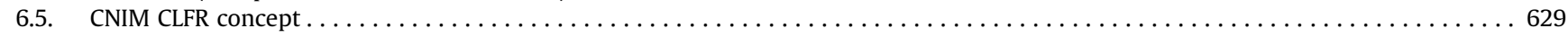

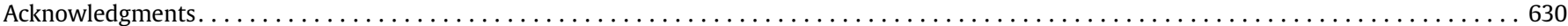

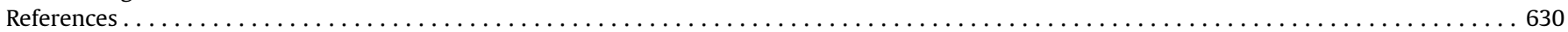

\section{Introduction}

In the context of a world where primary energy consumption is constantly increasing, and where the climate change most opti mistic scenario is now the limitation of the global average tem perature rise above pre industrial level to $2{ }^{\circ} \mathrm{C}$, renewable elec tricity generation has a major role to play. Concentrated solar power (CSP) plants use the sun's direct normal irradiation to generate electricity using an intermediate conversion into thermal energy and a thermodynamic cycle. Current installed capacity worldwide is about $4 \mathrm{GWe}$ [1], which is still a low figure as com pared to photovoltaics. However, in its "hi Ren" scenario, the International Energy Agency envisions a CSP contribution to the global electricity production of about $11 \%$ by 2050 [1]. It should be noted that this figure remains almost unchanged since the pre vious report [2], although CSP development was lower than expected in this intermediate period.

Among the several technologies used to collect heat in line focus CSP technologies, the use of water/steam as both heat transfer fluid (HTF) and working thermodynamic cycle fluid con stitutes the so called direct steam generation technology (DSG). It offers several advantages compared to the synthetic oil that is used in most line focus plants: the fluid is heated up to a higher temperature, and the overall configuration is simpler thanks to the absence of HTF piping and heat exchange components [3]. Although the potential of generating steam directly in the absor ber tubes was identified in the early 80's [4], first studies to apply this technology to line focus systems go back to the early 90's, with research effort regarding two phase flow inside horizontal tubes $[35,6]$. Since then, numerous studies and research projects have been carried out, many of which surrounding the DIrect Solar Steam (DISS) experimental facility in Almeria [7]. A recent review by Hirsch et al. [8] gives a good overview of today's state of the art about direct steam generation. Recent studies about the potential of DSG compared to synthetic oil, considering the latest knowl edge and technologies, are also available. The studies by Eck et al. [9] and Feldhoff et al. [10] show a potential reduction of the levelized electricity cost (LEC) up to $11 \%$. They did not however include the use of thermal energy storage, which is a major asset of solar thermal electricity. This was done in a more recent study by Feldhoff et al. [11], in which it was shown that with the current state of the art on thermal storage, the LEC of a DSG plant could actually be higher than the one of an equivalent oil plant. Several leads are proposed to reduce the LEC, including the use of a spe cific DSG plant architecture, known as "once through". That architecture is however less applied today, mainly because it requires a more complex control structure.
The control system design of a CSP plant is critical to its proper operation since it has to handle the natural transient condition of solar irradiation, and it is even more important in the case of a DSG system in which the magnitude of the transient phenomenon is increased by the presence of two phase flow inside the absorber tubes. The objective of this paper is to provide a state of the art of the control systems used for direct steam generation in line focus CSP plants. The focus is mainly on the methods proposed in lit erature, and the actually applied systems as well, although infor mation about operating power plants is difficult to obtain. In the first section of the paper, some general notions are given about DSG and how it is operated. The next three sections are dedicated to the control systems for each operation mode, and a last section focuses on operational experiences from the few currently running commercial plants. Advanced control being a vast and complex research field, some basic explanation is given each time a new control method is mentioned.

\section{Direct steam generation in linear concentrating systems}

\subsection{Overall layout and physical considerations}

As many of the conventional power plants, CSP plants use a thermodynamic steam Rankine cycle to generate work that drives an electricity generator. It therefore seems obvious that generating steam directly in the solar field reduces the complexity of the overall system. Fig. 1 below shows an ideal steam Rankine cycle (1a) and a simplified diagram of its application (1b) in a DSG plant (Fresnel collector is used for the schematic). Some details are also given for the involved thermodynamics processes. Numbered points on the figure refer to thermodynamic states between the described processes.

- 1-2-3-4: Isobaric heat transfer. Feedwater is pre heated to liquid saturation conditions either solely in the solar field or partly in a reheater and in the solar field. Water is then vaporized and steam is superheated in the solar field. Depend ing on the operation mode, vaporization and superheating take place in the same section, or separate sections. The process is ideally isobaric, but pressure drop actually takes place in the absorber tubes and the external piping.

- 4-5: Isentropic expansion. Superheated steam decreases in enthalpy by being expanded in the turbine. The ideal process is isentropic, but entropy actually increases which leads to less energy transfer on the turbine blades. Depending on the power 
block setting, expansion brings steam to vapor saturation con ditions, or to superheated conditions again.

- 5-6: Isobaric heat rejection. Steam is desuperheated (if superheated conditions at 5), condensed, and subcooled in a
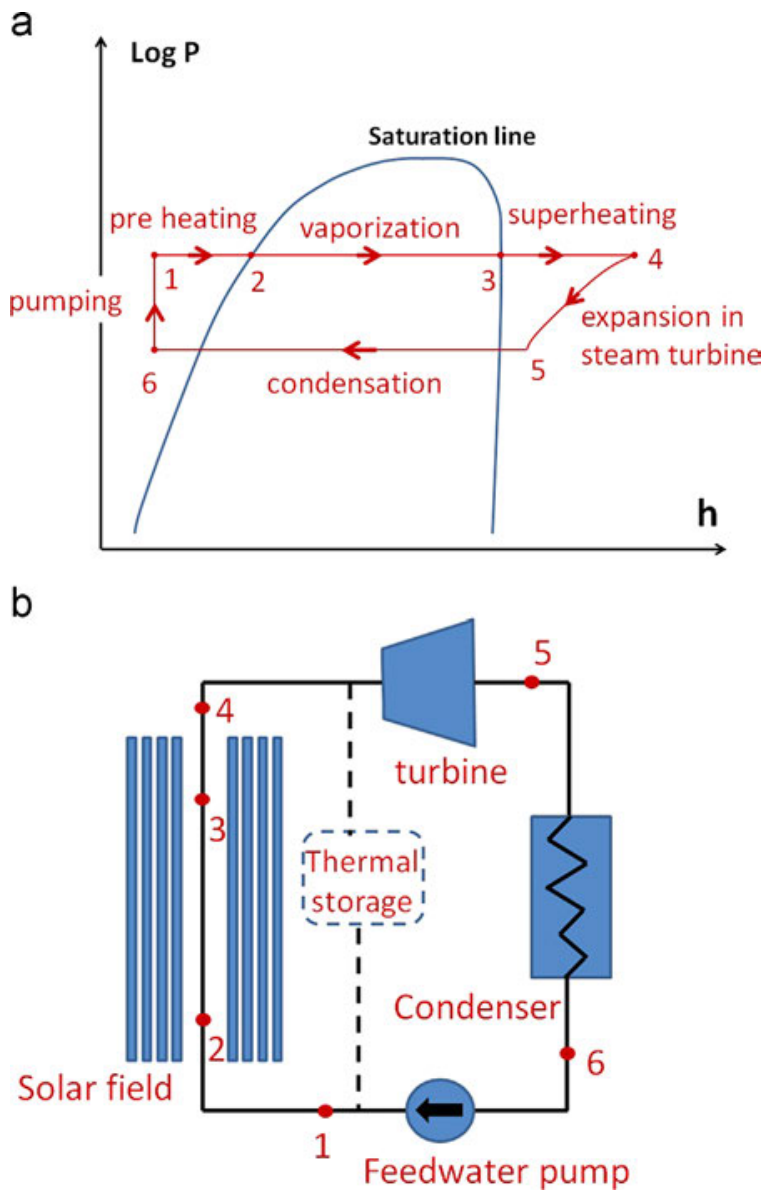

Fig. 1. Ideal steam Rankine cycle on a pressure-enthalpy diagram (left, a) and its layout in a DSG plant (right, b). heat exchanger. The process is once again ideally isobaric, but pressure losses are actually observed in the condenser.

- 6-1: Isentropic compression. Condensed water pressure is raised in the feed pump, and brought to the solar field operating pressure.

Pre heating, vaporization, and superheating take place through different phenomena, each associated with its own thermo hydraulic properties. Pre heating and superheating are single phase convective heat transfer, with different heat transfer coefficients. Vaporization in the absorber tubes is a two phase convective flow boiling phenomenon, with very specific proper ties, and the scientific community still has relatively few knowledge of the precise dynamics taking place, in particular for horizontal configurations. Most of the calculations that are related to this field, pressures drops and heat transfer coefficients in particular, are only carried out through the use of empirical correlations.

\subsection{Operation modes for the direct steam generation}

Three main concepts, or operation modes, were identified in the early phase of the DISS project [12]: the recirculation concept, the once through concept, and the injection concept, all pictured in Fig. 2.

\subsubsection{Recirculation operation mode}

With recirculation, water is preheated and vaporized in a specific section, and superheated in another one. Water is fed at the inlet of the vaporizer, heated up to saturation conditions, and then vaporized, below vapor saturation conditions. The two phase fluid flows into a field separator, where steam is separated from the liquid water. A recirculation pump drives the liquid back to the vaporizer inlet, where it is mixed with the feedwater from the power block outlet, and saturated steam is fed to the inlet of the superheater. Steam quality at the vaporizer outlet is usually between $60 \%$ and $80 \%$ [8]. It should be high enough to avoid an excessively large recirculation pumping power (assuming feed water pumping is independently controlled, based on separator water level), and low enough to have a safety margin from tube dryout. The vaporizer outlet steam fraction can be defined by a a

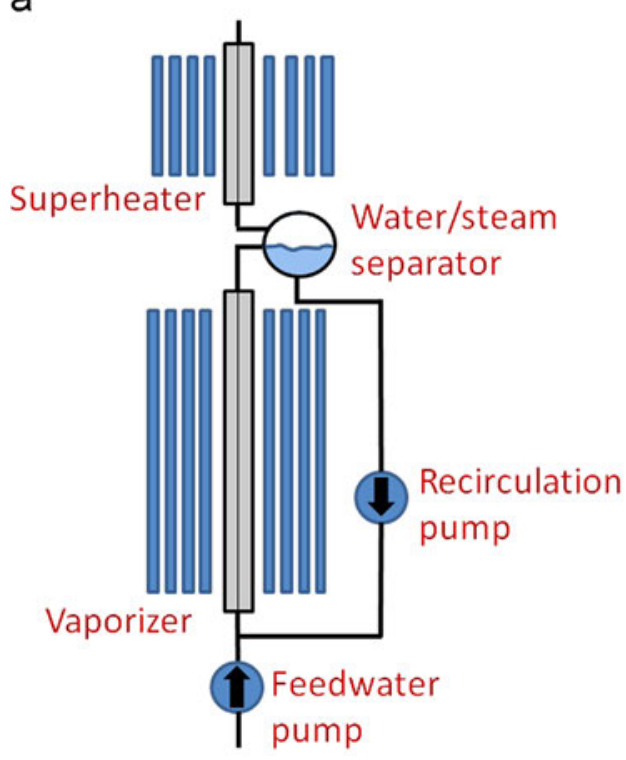

b

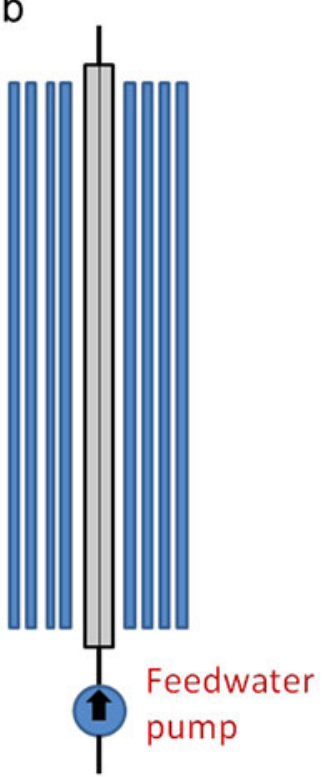

C

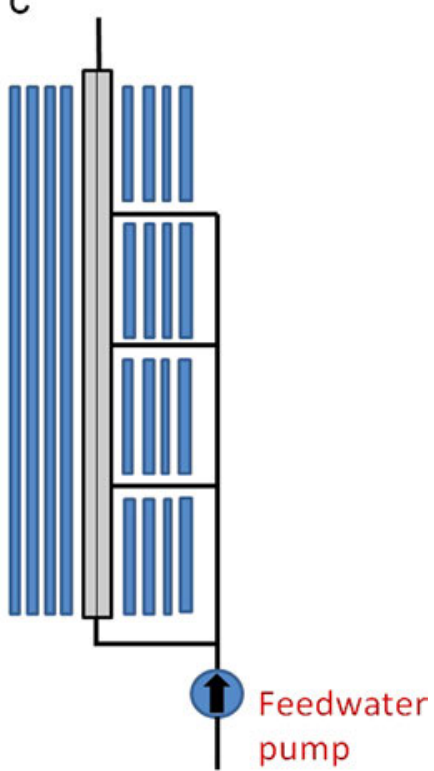

Fig. 2. The recirculation (left, a), once-through (center, b) and injection (right, c) concepts. 
thermodynamic state, as shown in equation (1). $x_{0}$ is the outlet steam quality, $P$ the operating pressure, $h_{0}$ is the outlet flow spe cific enthalpy, $h_{\text {sat,l }}$ the specific enthalpy at liquid saturation, $h_{\text {sat }, v}$. the specific enthalpy at vapor saturation. Those last two terms depend on the vaporizer operating pressure $P$, which is usually assumed to be constant for design and energy balance computa tions

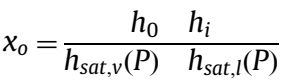

Outlet specific enthalpy can be computed from an energy bal ance, knowing the absorbed heat from the incoming solar irra diation on the tubes walls. Inlet specific enthalpy can be computed through another energy balance with the mixing of the inlet flows:

$h_{i}=\frac{Q_{\text {feed }} h_{\text {feed }}+Q_{\text {recir }} h_{\text {recir }}}{Q_{\text {feed }}+Q_{\text {recir }}}$

With feedwater mass flow rate $Q_{\text {feed }}$, feedwater specific enthalpy $h_{\text {feed }}$, recirculation mass flow rate $Q_{\text {recir }}$, recirculation water specific enthalpy $h_{\text {recir }}$. Let $r$ the ratio of the mass flow rates:

$r=\frac{Q_{\text {recir }}}{Q_{\text {feed }}}$

Vaporizer inlet flow specific enthalpy may then be written as:

$h_{i}=\frac{1}{1+r} h_{\text {feed }}+\frac{r}{1+r} h_{\text {recir }}$

If pressure is assumed to be constant throughout the vaporizer and if no heat loss is assumed in the recirculation piping,

$h_{\text {recir }}=h_{\text {sat }, l}(P)$

If feedwater flow rate and enthalpy are fixed, then outlet spe cific enthalpy, and thus steam quality, depends on only one con trollable parameter, the recirculation mass flow rate.

\subsubsection{Once through operation mode}

Once through is a solar field architecture where preheating, vaporization and superheating of the water/steam take place without separation. There is no water/steam separator at the end of the vaporizer section and the whole flow rate goes through the inlet of the solar field. Dry superheated steam is expected at the solar field outlet, and feedwater flow is at the enthalpy and pressure condition of the power block outlet. The transition points between preheating and vaporization and vaporization and superheating are not clearly predictable since the behavior of the system is very dynamic, but those positions can be roughly estimated. Fig. 3 shows a simplified diagram of the flow inside a single horizontal absorber tube [13]. For sizing needs, using some assumptions in steady state conditions, one can estimate the positions where enthalpy reaches $h_{\text {sat, } l}(P)$ and $h_{s a t, v}(P)$, by simple energy balance computations.

\subsubsection{Injection operation mode}

With the injection architecture, several injectors are dispatched along the solar field such that the flow rate is injected in small quantities in each of them. As for the once through concept,

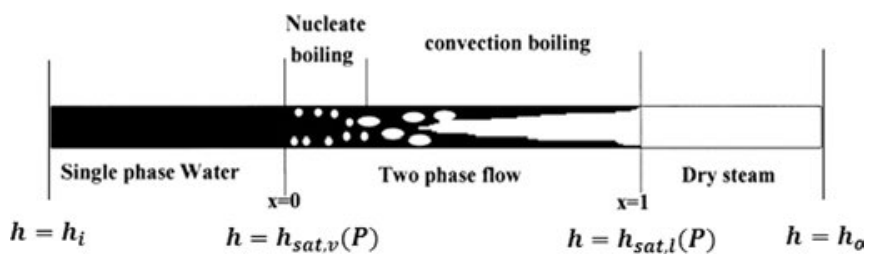

Fig. 3. Diagram of the two-phase flow in an absorber tube, reprinted from [13]. pre heating, vaporization and superheating take place in the same absorber lines. Knowledge of the transition regions is therefore also difficult, and the control systems designs require the assumptions that flow energy states are known at the injection positions. In the case of a parabolic trough collector field, the injections are done at the inlet of each collector.

\subsubsection{Considerations for the control system}

The steam generation has to be controlled with a system that strongly depends on the configuration itself, which is why it seemed appropriate to give some insight about DSG solar field architectures. The main requirement of the solar steam generation system is to provide live steam to the steam turbine and thermal storage at pressure and temperature conditions as stable as pos sible. In practice, because of the input energy transients, some being slow and deterministic (daily and seasonal cycles), some being fast and non deterministic (clouds passages), transients are almost impossible to avoid. Ideally, irradiation transients should only affect the amount of available steam, and not its quality (in the general sense). In the early studies of the direct steam gen eration concept, the issue of controllability of the convective flow boiling process was raised at the beginning [14]. This led to the fact that an important part of the subsequent research in the DISS program was dedicated to control strategies [12].

The bad tolerance of the turbine blades to large temperature transients is one of the reasons why temperature stability is to be achieved as best as possible, with the objective of avoiding large temperature overshoots and drops. Steam turbines have been working now for more than a century, and standards [15] from the International Electrotechnical Commission (IEC) are available. From this standard, limits about the steam quality at the inlet can be extracted. Birnbaum et al. [16] summed them up, and presented them as in Fig. 4.

In terms of absolute temperature, the value not to be exceeded appears to be $28 \mathrm{~K}$ above the rated condition. In terms of tran sients, the standards do not mention the allowable values during turbines operation, as they are specific to the models and manu facturers. However, the authors mention a rule of thumb that turbines in the range of 50 to $150 \mathrm{MW}$ should not go through temperature transients larger than $5 \mathrm{~K}$ per minute.

As it is presented in the following sections, most control sys tems make the use of a PI controller, whether solely or as a part of a more complex structure. In both cases the issue of its parameters definition is to be addressed. Controller parameters tuning is a very vast research area, and is not in the scope of this study. However, the specific tuning methods that are used in the field of line focus direct steam generation are presented. Most of the time, the process to control is modeled with transfer functions, useful for studying dynamic behaviors. From the transfer functions, parameters tuning can be carried out, and methods are explained in the dedicated sections.

\section{Control systems for the recirculation operation mode}

From simple PI and feedback to more complex structures, this section aims at summing up the different control structures pro posed in the literature to control a DSG solar field using the recirculation concept.

This concept solves the issue of the engineers and researchers' inability to exactly predict the location of the end of vaporization in the tubes. Indeed, more water that can be vaporized is injected in the evaporator, leading to a steam fraction below unity at the outlet. This architecture implies a more complex and costly solar field, as more equipment is needed: field separator, supplementary piping (and therefore more pressure losses), a recirculation pump (and therefore 


\begin{tabular}{lll}
\hline Parameter & Limit & Duration \\
\hline Turbine inlet temperature & $\begin{array}{l}\text { Rated temperature } \\
<+8 \mathrm{~K} \text { exceeding rated temperature } \\
<+14 \mathrm{~K} \text { exceeding rated temperature }\end{array}$ & $\begin{array}{l}\text { Annual average must be the rated temperature or below } \\
\text { Annual average must be maintained } \\
\text { Annual average must be maintained and accumulated duration }<400 \mathrm{~h} \\
\text { per year } \\
\text { Annual average must be maintained, accumulated duration }<80 \mathrm{~h} \text { per } \\
\end{array}$ \\
& $<+28 \mathrm{~K}$ exceeding rated temperature & year, max. duration $<15$ min \\
& $+28 \mathrm{~K}$ exceeding rated temperature & Not allowed to exceed \\
Turbine inlet pressure & Rated pressure & Annual average must be the rated pressure or below \\
& $<105 \%$ of rated pressure & Annual average must be maintained \\
& $<120 \%$ of rated pressure & Annual average must be maintained and accumulated duration $<12 \mathrm{~h}$ \\
\end{tabular}

Fig. 4. Limits of steam and pressure at turbine inlet, according to standards [15], and presented by (and reprinted from) [16].

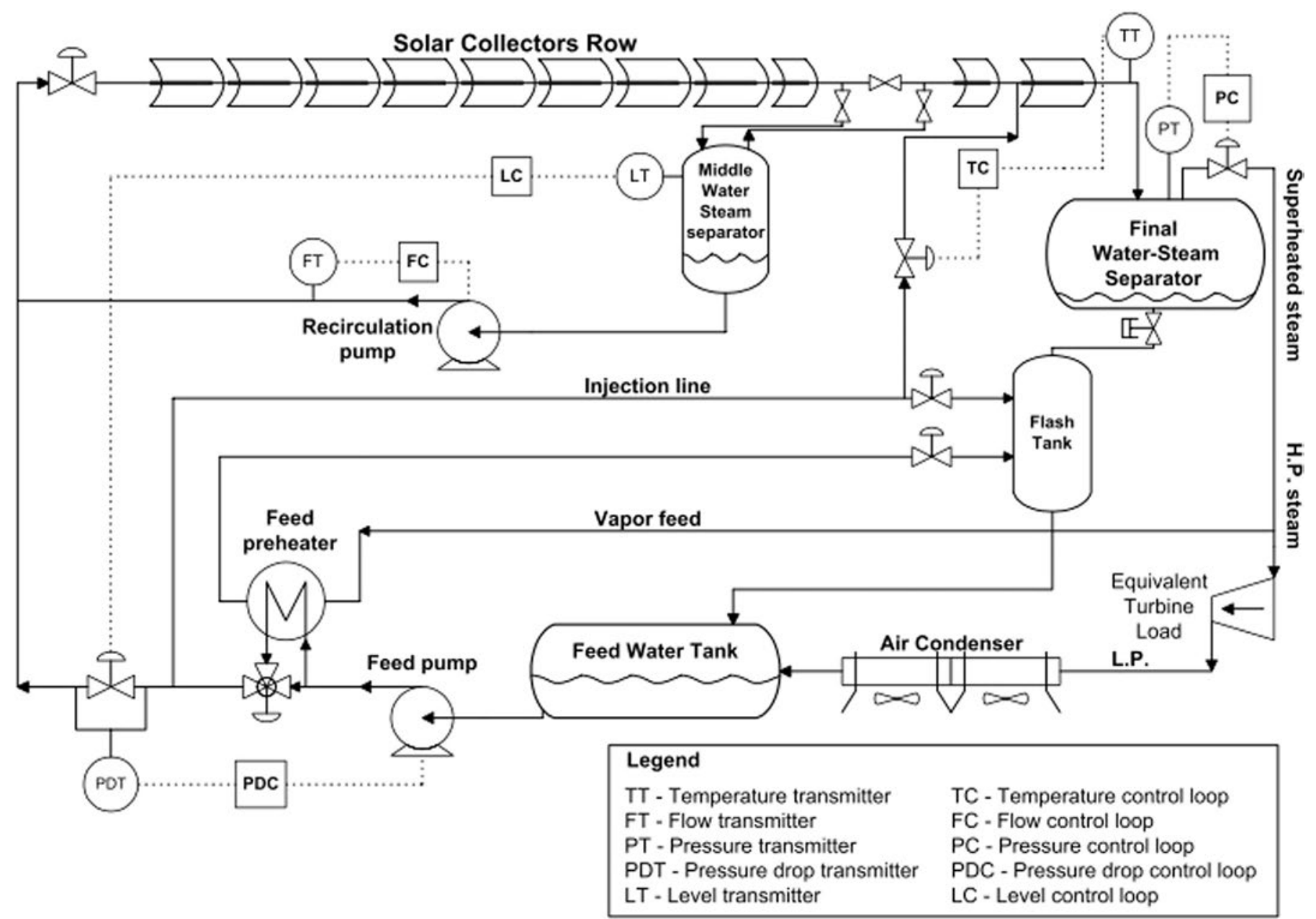

Fig. 5. Diagram of the DISS loop in recirculation mode with its control loops, reprinted from [17].

more parasitic electricity consumption). However, the concept offers more stability by bringing more inertia to the steam generation and adds a controllable parameter, the recirculation flow rate, which has a significant impact on the steam quality. The uncertainty of the transition between saturated and superheated steam also leads to durability and safety issues in the case of the once through mode, which is not the case with recirculation.

\subsection{Control structures using solely PI with feedback}

\subsubsection{Single row vaporizer and superheater control}

Earlier research work on the recirculation operation mode was carried out with the DISS loop in Almeria. Valenzuela et al. [17] propose a feedback control system, based on proportional integral controllers, pictured in Fig. 5.

Starting with the superheating section, the proposed control loops for this configuration are detailed below. Describing these loops also gives some insight about the main dynamics of the system.

- Outlet superheated steam temperature control loop: the temperature is controlled by a valve that injects feedwater in the last collector. "Fresh" water is injected into the superheated steam and instantly vaporized to decrease temperature;

- Outlet superheated steam pressure control loop: live super heated steam flows into a final separator before being fed to the 
turbine. Pressure is maintained constant by the adjustment of a valve aperture. The solar field therefore works in constant pressure mode;

- Final separator liquid level control loop: an on off control is used to avoid a high liquid level in the superheated steam separator;

- Recirculation control loop: in the vaporizer, recirculation is maintained to a constant flow rate by controlling the recircu lation pump. This control is necessary because irradiation transients on the receivers generate strong changes in pressure drop across the pump. This type of control therefore does not include steam fraction control at the vaporizer, but makes the operation safer since a minimal flow rate is always ensured;

- Separator level control loop: the feed valve at the inlet of the solar field controls the liquid level of the medium separator. If recirculation flow rate is constant, and with some other assumptions, steam quality depends on the feedwater flow rate. Therefore, adjusting feedwater valve aperture controls the medium separator level. This loop is strongly affected by DNI (Direct Normal Irradiance) transients: if irradiation drops, then steam production drops and tank liquid level increases;

- Feedwater valve pressure drop control loop: the feedwater pump controls the pressure drop across the feedwater valve: it is maintained to a specific value by adjusting the rotational speed. Changes in the feedwater tank pressure has an influence on the valve pressure drop, therefore control is necessary.

All control loops are based on a simple feedback structure (pictured in Fig. 6) with a PI controller fitted with an antireset windup option.

That structure is used to handle the effects that arise from the use of a saturated actuator. Indeed, most control loops have saturation limits since the actuator is a solar field working para meter (valve aperture, pump rotational speed, etc.) with physical limits. If controller output signal goes beyond saturation values, there is no more effect on the actuator, but the integral of the feedback error keeps growing, therefore leading to a controller computing a wrong correction signal. This is known as "reset windup". Antireset windup schemes are designed to adapt con troller operation to the saturation values by "canceling" its integral part when the actuator is saturated. The effect is that the con troller output value stays close to the actuator saturation values. Fig. 7 shows the structure for a PID controller.

The PI controller parameters are determined by the use of a model approximation method, experimentally applied: A step disturbance on the actuator variable is used at the input, and the controlled variable response is monitored at the output. A basic model with a typical transfer function (first or second order, delay term, etc.) is then fitted on this reaction curve. PI parameters are then computed with empirical correlations based on the para meters of these models. They are then adjusted for the overall system to have safe theoretical stability margin. For more details about controller parametrization from approximated models, see reference [18].

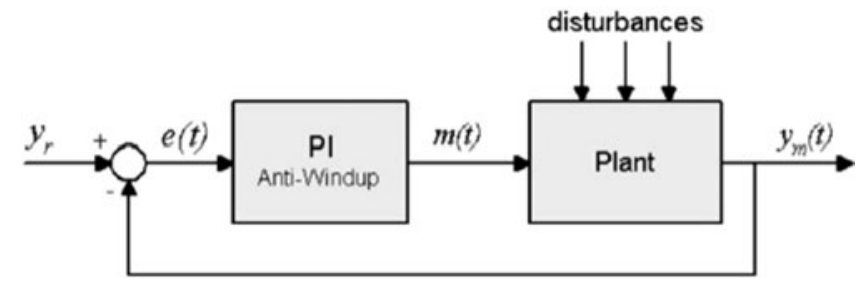

Fig. 6. PI control principle, reprinted from [17].

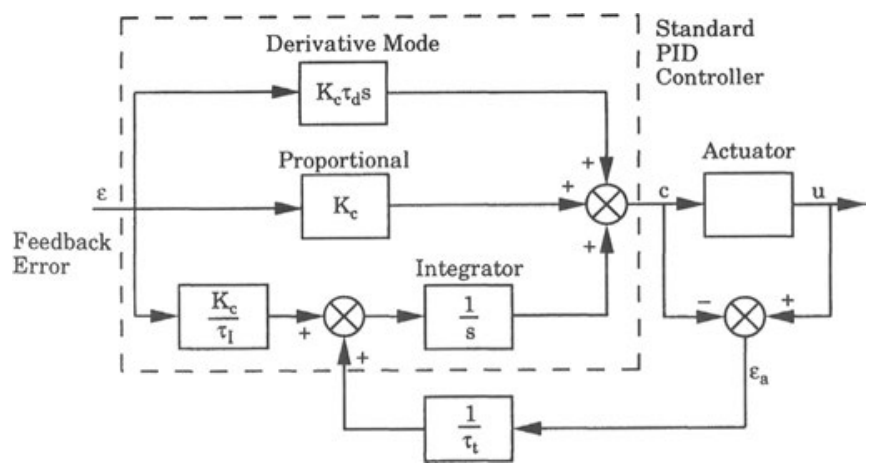

Fig. 7. PID controller with an antireset windup scheme, reprinted from [18].

Fig. 8 sums up the fitted models for the loops dynamics and the proposed PI controller parameters, after final readjustments.

The recirculation pump, feed pump, and outlet steam pressure controls loops are modeled with a first order model:

$G(s)=\frac{K}{s+\tau}$

The middle separator level control loops is modeled with a delayed integrator transfer function. The open loop system is indeed unstable when given a step disturbance.

$G(s)=\frac{K}{s} e^{-\tau s}$

Finally, the outlet steam temperature control loop is modeled with a delayed second order transfer function:

$G(s)=\frac{K}{s^{2}+a_{1} s+a_{0}} e^{-\tau s}$

One can notice that the time constants orders of magnitude are very different between the recirculation flow rate control loop and the middle separator level control loop. It is in fact a glimpse of the dynamics taking place in such a system, where water/steam flows inside long tubes and holds large process dead time (and thus explaining large reset time for the involved control loop). The recirculation control loop, on the contrary, is quite fast in com parison because the pump brings fast pressure and flow rate changes to the flow.

In this Valenzuela et al. [17] study full day experiments are carried out with three different operating pressure levels: 30, 60 and 100 bars. Conclusion is that controllability is easier to achieve with higher operating pressure, and that the proposed control system is satisfactory for handling irradiation changes, including relatively fast changes due to clouds passing over the solar field.

Another simulation study by Birnbaum et al. [16] uses a var iation of the superheater outlet temperature control method pre sented above, with a cascade control system. It uses a feedback of the temperature at both the outlet and at the middle of the last collector. The structure is pictured in Fig. 9. The master loop ("LEAD") uses the outlet temperature measurement, the slave loop the middle measurement. The parametrization of the controllers is done the same way as in Koch et al. work [19], described in the next section. The study simulation results suggest that tempera ture deviations due to irradiation disturbances go beyond critical values of the steam turbine standards. Suggestions are therefore made to add more thermal inertia to the superheater, or to use a spray attemperator before the turbine inlet.

\subsubsection{Multi row superheater outlet temperature and mass flow control}

A study by Koch et al. [19] models a superheating section with several rows, all connected to the same field separator. Each row is made of a two parabolic trough collectors connected in series, with 
Recirculation mode: models and PI control loops parameters

\begin{tabular}{|c|c|c|c|}
\hline \multirow[t]{2}{*}{ Single feedback control loop } & \multirow[t]{2}{*}{ Model } & \multicolumn{2}{|l|}{ PI parameters } \\
\hline & & $K_{p}$ & $T_{i}(\mathrm{~s})$ \\
\hline Recirculation pump & $G(s)=\frac{0.0064}{s+0.1871}$ & $12.1 \% \mathrm{~kg}^{-1} \mathrm{~s}$ & 3.2 \\
\hline Feed pump & $G(s)=\frac{0.05223 \cdot 10^{-5}}{s+0.11765}$ & $0.95 \% \mathrm{bar}^{-1}$ & 6 \\
\hline Middle separator level & $G(s)=\frac{0.009}{s} e^{-340 s}$ & $\begin{array}{l}0.135 \% \mathrm{~mm}^{-1} \\
0.150 \% \mathrm{~mm}^{-1}\end{array}$ & 1300 \\
\hline Outlet steam pressure & $G(s)=\frac{-0.001706-10^{-5}}{s+0.00556}$ & $-5.4 \% \mathrm{bar}^{-1}$ & 184 \\
\hline Outlet steam temperature ( 30 bar) & $G(s)=\frac{1.657 \cdot 10^{-4}}{s^{2}+0.016 s+7 \cdot 9 \cdot 10^{-5}} e^{-100 s}$ & $0.39 \%{ }^{\circ} \mathrm{C}^{-1}$ & 520 \\
\hline Outlet steam temperature ( 60 bar) & $G(s)=\frac{1.051 \cdot 10^{-4}}{s^{2}+0.0169 s+7.9 \cdot 10^{-5}} e^{-80 s}$ & $0.78 \%{ }^{\circ} \mathrm{C}^{-1}$ & 700 \\
\hline Outlet steam temperature (100 bar) & $G(s)=\frac{1.381 \cdot 10^{-4}}{s^{2}+0.0223 s+1.384 \cdot 10^{-4}} e^{-90 s}$ & $1.08 \%{ }^{\circ} \mathrm{C}^{-1}$ & 700 \\
\hline
\end{tabular}

Fig. 8. Control loops fitted models and PI parameters, reprinted from [17].

an injection cooler between them, and a valve at the outlet of the second one. The authors show that the use of these valves, which allow for the control of the mass flow distribution in all the parallel rows, is useful to handle heterogeneous irradiation disturbance without strongly affecting the "performance" of the superheater.

The presented work is original in the way that it proposes a global method for controlling several parallel rows with individual actuators. It includes nonlinear dynamic modeling with acausal equations, as well as linear modeling for the design of the control system. A description of the latter is proposed in this section, with the general design steps. Details can be found in [19].

3.1.2.1. Single row modeling. From the energy balance equations in the flow and the tube wall, a linear model is derived using the following equation (example for the wall to fluid heat transfer coefficient) $\alpha$ :

$\alpha(t)=\bar{\alpha}+\Delta \alpha(t)$

with $\bar{\alpha}$ the steady state value and $\Delta \alpha(t)$ a small perturbation. From the linearized equations, transfer functions are derived. In the presented work, the outlet temperature is the controlled variable, hence the output of the derived transfer functions. Inputs are the heat flux, the input mass flow rate, and the inlet flow temperature. The transfer functions that are eventually obtained all include a common term: the transfer function $G_{0}(s)$ made of a delay term and a transcendent term.

$G_{0}(s)=e^{-t_{d} s} e^{-\frac{K_{F} s}{s+K_{R} s}}$

The delay term is eliminated with a Padé approximation, and the transcendent term is approximated with a method proposed by Marsik and Fortova [20], a $P T_{n}$ block, leading to:

$G_{0}(s)=\left(1 \frac{t_{d}}{2} s / 1+\frac{t_{d}}{2} s\right) \frac{1}{\left(T_{t} s+1\right)^{n}}$

with

$n=\frac{K_{F}}{2} \quad 2$

and

$T_{t}=\frac{K_{F}}{K_{R} n}$

3.1.2.2. Multi row modeling. The overall superheating section, consisting of $n_{r}$ identical rows, is modeled with a matrix linear

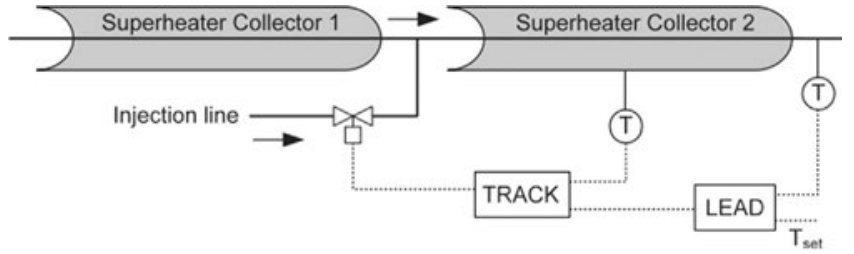

Fig. 9. Superheater cooling injection control proposed by (and reprinted from) [16].

mapping that links the valves aperture changes $\Delta \boldsymbol{H}$ to the mass flow changes $\Delta \dot{\boldsymbol{M}}$ :

$\Delta \dot{\boldsymbol{M}}=\boldsymbol{K}_{M H} \Delta \boldsymbol{H}$

with

$\boldsymbol{K}_{M H}=\left(\frac{\partial \boldsymbol{f}}{\partial \dot{\boldsymbol{M}}}\right)^{-1} \cdot \frac{\partial \boldsymbol{f}}{\partial \boldsymbol{H}}$

The function $f$ is derived from two physical statements: the total pressure losses are identical in each row (since all rows are connected to the same turbine header and steam separator outlet) and the total mass flow rate is conserved. Pressure loss in a single row $i$ is the sum of the pressures losses in both collectors (pre cooler and post cooler) and the loss induced by the valve:

$\Delta p_{\text {loss }, i}=\Delta p_{i, 1}+\Delta p_{i, 2}+\Delta p_{i, v}$

The pressure loss induced by the valve is a function of the injection mass flow in the collector $\dot{M}_{i}$, the cooler mass flow rate $\dot{M}_{i n j, i}$, the fluid density at the control valve $\rho_{F v, i}$ (a function of the turbine inlet pressure $p_{\text {turb }}$ and the fluid temperature at the superheater outlet $T_{F a, i 2}$ ), the control valve constant parameters $K_{v 0}$ and $K_{v s}$ and relative lift $H_{i} / H_{100}$. The $\boldsymbol{K}_{M H}$ matrix is decom posed between a scalar gain $k_{M H}$ and a square symmetric matrix. The linear mapping from the valve aperture $\Delta \boldsymbol{H}$ to the pre cooler (index 1) collector outlet temperature $\Delta \boldsymbol{T}_{\mathbf{F a}, 1}$ is then derived:

$\Delta \boldsymbol{T}_{F a, 1}=\boldsymbol{G}_{M, 1} \boldsymbol{K}_{M H} \Delta \boldsymbol{H}$

with $\boldsymbol{G}_{M, 1}$ the diagonal matrix of the single rows transfer functions

$G_{M}(s)=\frac{\Delta T_{F a}}{\Delta \dot{M}}$

3.1.2.3. Control system structure. The idea of the proposed control system is to aim for a homogeneous temperature at the pre cooler 
collector outlet of each row. It is then based on a feedback control of the difference of each outlet temperature to the arithmetic average of the outlet temperatures, with a constant setpoint of zero. In other words, the pre cooler collector outlet temperatures must be as close as possible from each other, whatever the abso lute temperature is. The proposed system uses a PI controller with adaptive parameters, and scaling of the controlled plant.

The temperature vector $\Delta \boldsymbol{T}_{F a, 1}$ is transformed into a "differ ence to average" temperature vector $\Delta \boldsymbol{T}_{F a, 1}^{\text {diff }}$ with a transformation matrix:

$\Delta \boldsymbol{T}_{F a, 1}^{\text {diff }}=\boldsymbol{A}_{\text {trans }} \Delta \boldsymbol{T}_{F a, 1}$

The scaling matrix $\boldsymbol{S} \boldsymbol{c}_{\boldsymbol{u}}$, used to input diagonal plant scaling terms, is also introduced. The plant generating the controlled vector output $\Delta \boldsymbol{T}_{\mathrm{Fa}, 1}^{\text {diff }}$ from the controller signal is therefore:

$\boldsymbol{G}_{T_{\text {Fa, }}^{\text {diff }}}=\boldsymbol{A}_{\text {trans }} \boldsymbol{G}_{M, 1} \boldsymbol{K}_{M H} \boldsymbol{S} \boldsymbol{c}_{\boldsymbol{u}}$

And the general control system structure is pictured in Fig. 10: The transfer function of the irradiance disturbance vector to the output, and to the control variable are:

$$
\begin{gathered}
\Delta \boldsymbol{T}_{F a, 1}^{d i f f}=\left(\boldsymbol{E y e}\left(\boldsymbol{n}_{\boldsymbol{r}}\right)+\boldsymbol{G}_{T_{F a, 1}^{\text {dif }}} \boldsymbol{K}\right)^{-1} \boldsymbol{A}_{\text {trans }} \boldsymbol{G}_{I, 1} \Delta \boldsymbol{I}_{1} \\
\Delta \boldsymbol{H}=\boldsymbol{S} \boldsymbol{c}_{\boldsymbol{u}} \boldsymbol{K}\left(\boldsymbol{E} \boldsymbol{E} \boldsymbol{e}\left(\boldsymbol{n}_{\boldsymbol{r}}\right)+\boldsymbol{G}_{T_{\mathrm{Fa}, 1}^{\mathrm{dif} f}} \boldsymbol{K}\right)^{-1} \boldsymbol{A}_{t r a n s} \boldsymbol{G}_{I, 1} \Delta \boldsymbol{I}_{1}
\end{gathered}
$$

$\boldsymbol{E y} \boldsymbol{e}\left(\boldsymbol{n}_{\boldsymbol{r}}\right)$ is the identity matrix. The term $\boldsymbol{A}_{\text {trans }} \boldsymbol{G}_{I, 1}$ is the irra diation disturbance transfer function to the disturbance of the temperature difference from the average vector. $\boldsymbol{M}$ is the resulting matrix. The diagonal terms $M_{i j, i}$ j represent the influence of an irradiation disturbance on a collector on the same collector tem perature outlet disturbance. Other terms $M_{i j, i \neq j}$ ( $i$ th row, $j$ th column) represent the influence of the $j$ th collector disturbance on the $i$ th collector outlet temperature disturbance.

\subsubsection{Multi row superheater controller parameterization}

3.1.2.4.1. Plant scaling. The scaling matrix $\boldsymbol{S c}_{\boldsymbol{u}}$ is used to com pensate the nonlinear gain of the control valve and the gain of the $\boldsymbol{G}_{M, 1}$ transfer function. It is constructed with two compensation matrices $\boldsymbol{K}_{M \text {,comp }}$ and $\boldsymbol{K}_{M H \text {,comp }}$ which are the "inverse" of $\boldsymbol{G}_{M, 1}$ and $\boldsymbol{K}_{M H}$, respectively, and a factor depending on the number of rows. It uses an approach borrowed from Internal Model Control, where the inverse of the transfer function of the process to control is computed for the controller design.

$\boldsymbol{S c}_{\boldsymbol{u}}=\boldsymbol{K}_{M, \text { comp }} \boldsymbol{K}_{M H, \text { comp }} \frac{n_{r} \quad 1}{n_{r}}$

3.1.2.4.2. Operating domain. An operating domain is defined, in terms of acceptable mass flow rates. The minimum flow rate should be defined by the maximum allowed outlet temperature before defocusing the collector $\left(410{ }^{\circ} \mathrm{C}\right)$ and by the minimum temperature that is fixed to $380^{\circ} \mathrm{C}$.

3.1.2.4.3. Requirements for the closed loop. The authors of the study determine that the valve controller tuning should be con servative, that is to say aiming for stability above all else, so that the injection coolers (each with their own single row control system, which is not dealt with here) can work properly. As quantitative requirement, it is decided that an irradiance dis turbance of $100 \mathrm{~W} / \mathrm{m}^{2}$ should lead to a temperature excess of less than $1{ }^{\circ} \mathrm{C}$, which implies considerations on the transfer functions. The control structure $\left(\boldsymbol{E} \boldsymbol{y} \boldsymbol{e}\left(\boldsymbol{n}_{\boldsymbol{r}}\right)+\boldsymbol{G}_{T^{\text {diff }}} \boldsymbol{K}\right)^{-1} \boldsymbol{A}_{\text {trans }}$ is defined with a bandwidth equal to the maximum crossover frequency of all the disturbance transfer functions of the operating domain.

3.1.2.4.4. Controller tuning. Each row has a PI controller, and adaptive control is used to compute the parameters. The gain $k_{p, i}$ is fixed for each row and the reset time is computed as a function of thermal conditions in the collector:

$T_{i}=T_{i f a c t o r} \frac{1}{2} \frac{\left(d_{a}^{2} \quad d_{i}^{2}\right) \rho_{R} c_{R}}{\alpha d_{i}}\left(1+\frac{n \quad 2}{6}\right)$

The time constant of the absorber tube wall $\frac{1}{2} \frac{\left(d_{a}^{2}-d_{i}^{2}\right) \rho_{R} c_{R}}{\alpha d_{i}}$ is also proposed in [21] for the injection cooling. $k_{p, i}$ and $T_{i, f a c t o r}$ are determined for each row, according to the requirements pre viously described.

The authors of the study also propose a slow integral control system (not detailed here) which ensures that the valves return to standard positions after disturbance rejections. The system directly controls the valve positions.

3.1.2.5. Study conclusion. The simulations of local transients on the superheater show that uncompensated asymmetric irradiance on the parallel rows leads to an injection cooling control that is not optimal. This demonstrates the positive effect of active mass flow distribution control in the case of a superheater connected to a central water/steam separator. On the control methodology, the authors use feedback control with an adaptive PI parametrization method, based on a relatively complex process model.

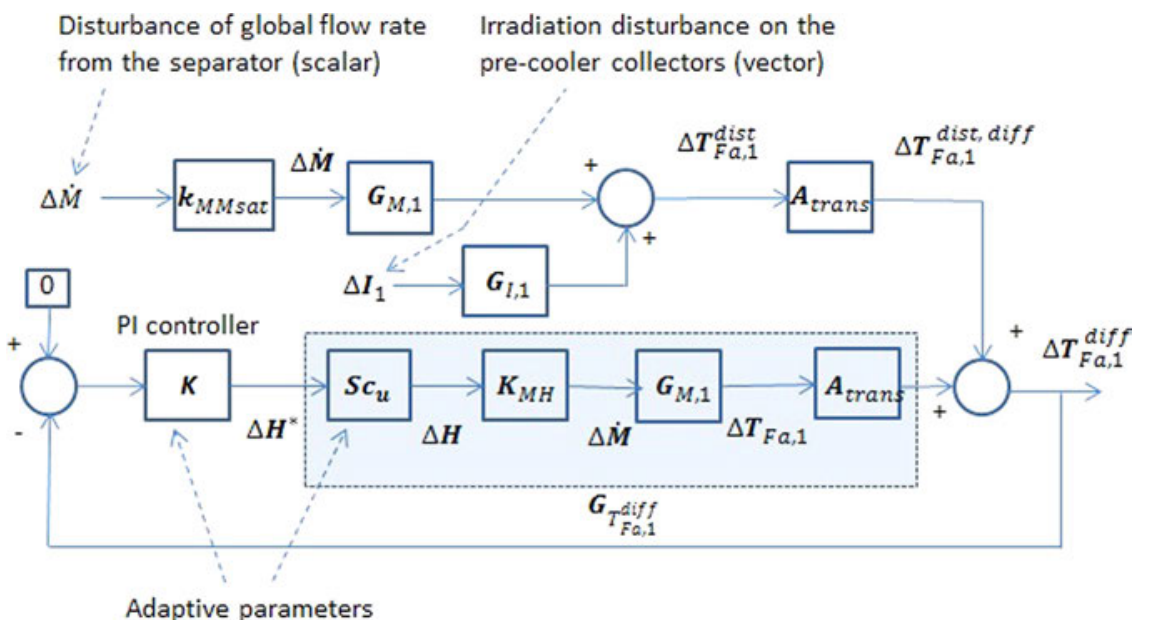

Fig. 10. General structure of the control system proposed by (and reprinted from) [19]. 


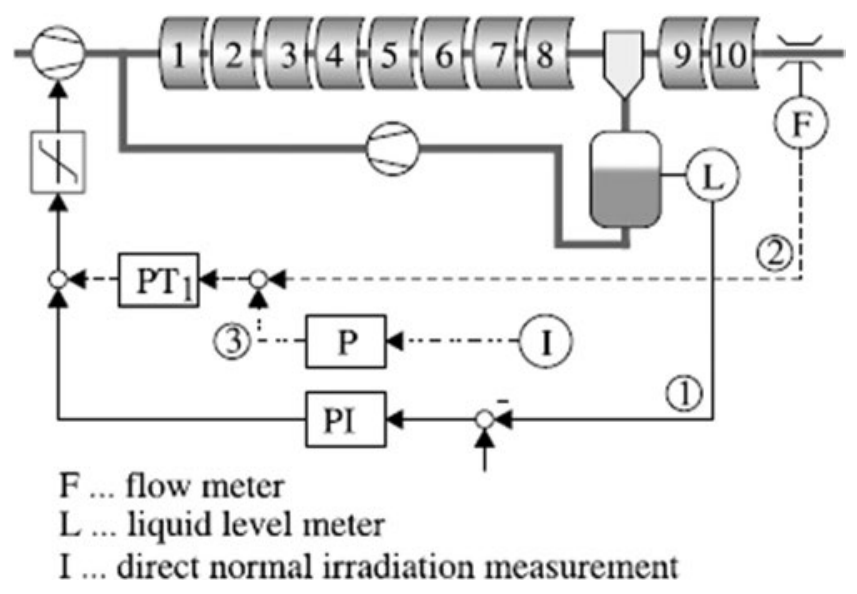

Fig. 11. Proposed control system for the feedwater flow control, reprinted from [21].

\subsection{Stuctures using feedforward control}

A DLR (Deutschen Zentrums für Luft und Raumfahrt, the German aerospace center) study by Eck and Hirsch [21] carried out the modeling of a pre commercial power plant as part of INDITEP (INtegration of the DIrect Steam Generation Technology for Electricity Production) project [22]. To study the effects of clouds related irradiation transients, control concepts are evaluated in their work.

\subsubsection{Vaporizer feedwater flow rate control}

A system including feedforward methods is proposed to control the feedwater flow rate, as pictured in Fig. 11. The basic control loop uses a PI controller to regulate the water level in the middle water/steam separator. PI parameters are determined "manually" with objectives on the overshoot and damping values, and a model of the process is used (no communication is made however on the model itself). Preliminary simulations of non controlled solar field models show large dead time in the pre heating section of the solar field (water/steam flows in long tubes), which implies that a low controller gain is to be used for stability reasons [18], and therefore leading to slow performance. The effect of adding mea surement or calculation of the actual steam production at the solar field outlet is studied. One option uses the feedback of the outlet measurement, another one the prediction of the steam production through an energy balance with the measured real time irradia tion, which is feedforward control. Adding one of these two options greatly improves the control system performance: simu lations of irradiation disturbance on collector 1 to 8 show reduced liquid water peaks in the water/steam drum.

For real application, it means that a solar field outlet flow meter would be necessary for the first option, and numerous solar field irradiation and temperature sensors for the second one. Simula tions show that control performance is slightly better with the direct steam flow rate measurement.

Another study by Dominguez et al. [23] proposes a control of the whole solar field solely through feedwater or feedwater and recirculation flow rates control. The measured DNI is used for feedforward action, and two controls methods are studied through simulation. The first one, referred to "feedwater control" consists in adapting the feedwater valve aperture to the measured DNI. The second one is referred to "enthalpy control" and consists in adapting the inlet flow enthalpy to the measured DNI, with the recirculation and feedwater valves. The effect of the same triple irradiation disturbance of [21] is studied. It is shown that the feedwater control method is more efficient to handle the dis turbance and prevent steam production and temperature over shoot. It is also shown however that the enthalpy control method a

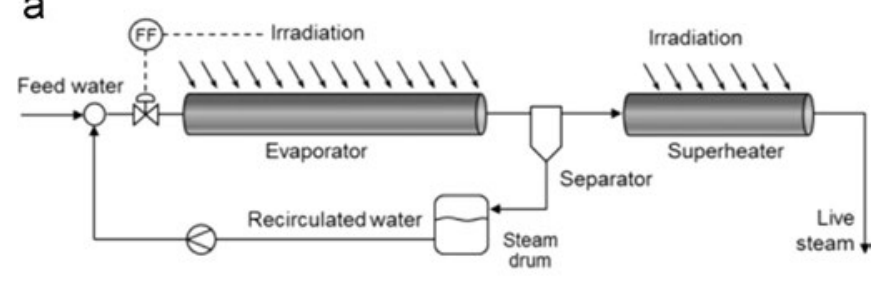

b

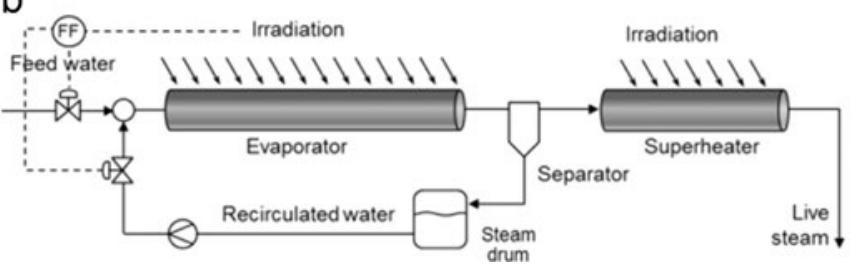

Fig. 12. Proposed control methods using feedforward action: feedwater control (a) and enthalpy control (b), reprinted from [23].

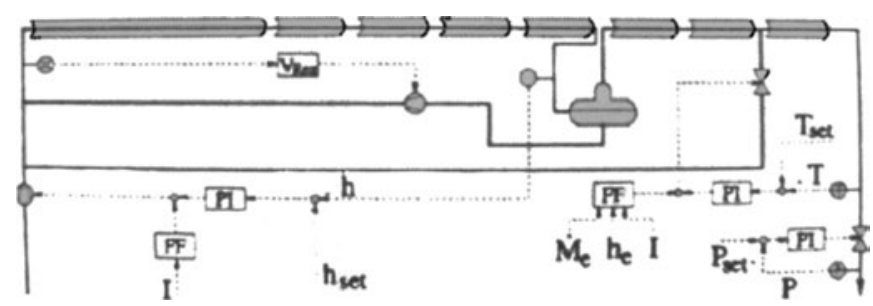

Fig. 13. Control system proposed by Eck and Steinmann for recirculation mode, reprinted from [24].

has a potential to avoid the steam production drop resulting from the irradiation drop. Fig. 12 pictures both concepts.

The use of feedforward control for the vaporizer section control was also proposed in an earlier study by Eck and Steinmann [24]. That work is rather dedicated to the injection operation mode (see dedicated section), but some insight is given on a proposed control system for recirculation, pictured in Fig. 13.

The enthalpy is controlled at the vaporizer outlet by a feedback PI controller, and a feedforward controller using irradiance mea surement. The signal controls the feedwater pump and is the sum of both control components. Another control loop using feedback and a PI controller ensures a constant recirculation ratio.

\subsubsection{Single superheater outlet steam temperature control}

The Eck and Hirsch [21] study proposes a superheater outlet steam temperature control based on the use of cold water injec tion in the last collector, as in Valenzuela et al. work [17]. The structure is shown in Fig. 14. A feedback loop using a PI controller to regulate an injection valve aperture is used along with a feed forward loop. A similar system is also proposed in [24].

The PI controller (feedback loop) parameters are adapted according to the flow situation in the superheater: A linearized model of the superheater (further detailed in Section 5.1) is used and its transfer function is approximated. Coefficients are extrac ted from the transfer function and used to compute the controller parameters. In parallel to this feedback loop, the feedforward loop computes the injection mass flow required to reach the set enthalpy condition at the superheater outlet, using real time measurements of irradiation, upstream flow rate and enthalpy. The cold water mass flow that is eventually injected is the sum of both loop signals. 


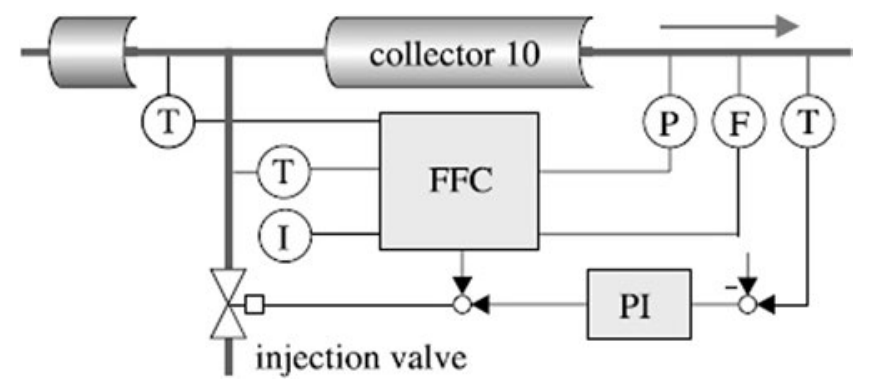

Fig. 14. Proposed structure for the superheater outlet steam temperature control, reprinted from $[21]$.

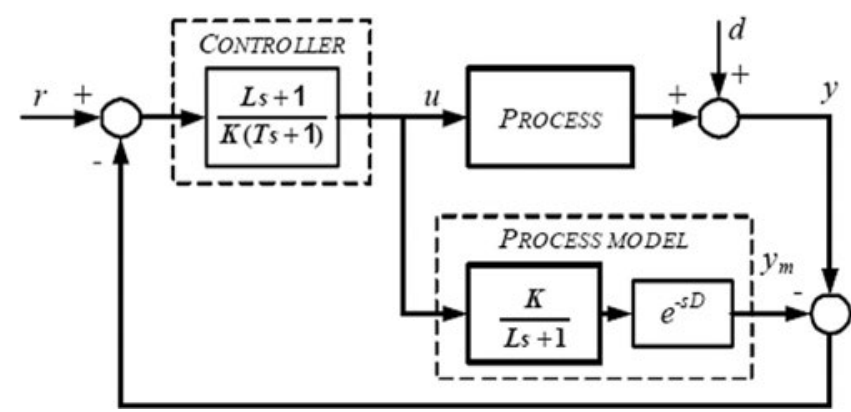

Fig. 15. A control structure using a Smith predictor, as presented in (and reprinted from) [25].

\subsection{Structures using "predictive" control: Separator level control with dead time compensation}

A tight control of the separator level allows for a smaller sizing, with benefits to the equipment cost. That is why some advanced control methods have been studied for this application. Valenzuela et al. [25] evaluate the use of dead time compensation methods. Controlling the water level with the solar field inlet regulation is indeed under the influence of large dead time because of the vaporizer inertia. Control systems using modified Smith predictors are simulated and experimented. A basic structure using a Smith predictor is shown in Fig. 15.

Smith predictor was proposed in the late 50 s to overcome the problem of controlling processes with large dead time. The idea is to subtract the process model output to the process actual output (actual output after disturbances) and to use that signal as feed back. The process model includes a delay term in the transfer function to account for the dead time of the process. The method is in fact part of the larger field of Internal Model Control, which we will mention in Section 5.2.2. As for the word "predictor", it should be used carefully here, since it only refers to the dead time prediction that is done through the modeling of the process, and not an actual prediction as in Model Predictive Control.

Valenzuela et al. use modified Smith predictors proposed by Matausek and Micic [26], and Normey Rico and Camacho [27], both pictured in Fig. 16, that are designed for controlling processes with an integrator like behavior and disturbance rejection.

The structure proposed by Matausek and Micic uses a con troller with an additional disturbance rejection term, which is in fact the difference between the process output variable and its estimated value by the model. $K_{r}$ and $K_{d}$ are the controller para meters to be tuned. In the study [25], $K_{r}$ is computed from a desired response time $T_{r}$ of the system and the process model gain. $K_{d}$ is computed through an analysis of the closed loop system equation. Both equations are written below:

$K_{r}=1 /\left(K T_{r}\right)$
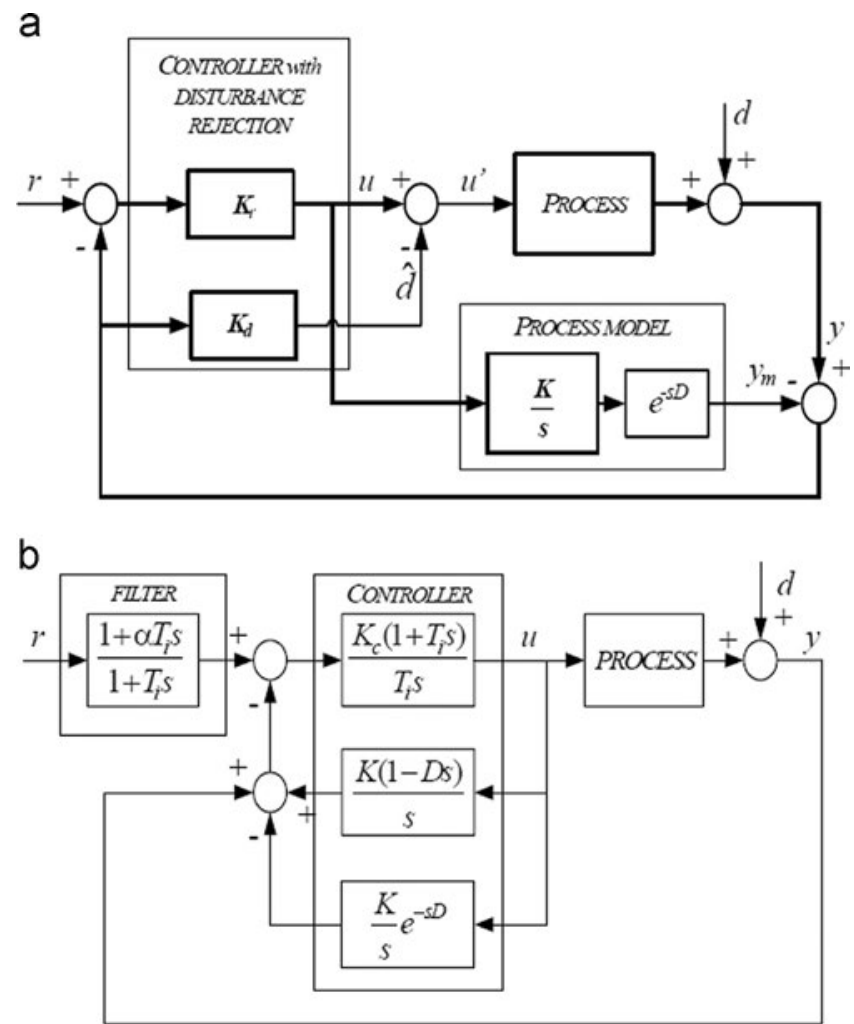

Fig. 16. Modified Smith predictors proposed by Matausek and Micic (a) and Normey-Rico and Camacho (b), as presented in (and reprinted from) [25].

$K_{d}=1 /(2 K D)$

$K$ and $D$ are the plant model parameters, respectively the process gain and the estimated dead time.

The Normey Rico and Camacho [27] structure is based on the control system proposed by (Watanabe and Ito, 1981) [28], with a supplementary filter for the setpoint signal. The controller para meters $T_{i}$ and $K_{c}$ are also computed from the value of a desired response time, as written in the equations below:

$T_{i}=2 T_{r}+D$

$K_{c}=\frac{2 T_{r}+D}{K\left(T_{r}+D\right)^{2}}$

The study evaluating the use of these control methods con cludes that the phases separator level control is satisfactory with simple feedback proportional and proportional integral control if the separator size is large (and therefore does not need a tight control), but the advanced methods taking dead time into account are necessary if a small separator size and tight control are in order.

As a more general observation, it can be stated that DSG solar field water/steam separators can be compared to conventional boilers, with common dynamics behavior issues that affect level control. A well know phenomenon is the so called "shrink and swell effect". The swell effect happens when pressure decreases in steam flow downstream of the separator (opening of a valve for example), pressure decreases in the separator and steam bubbles in the liquid water increase in volume, thus leading to an aug mentation of water level. The shrink effect is the opposite phe nomenon when pressure increases downstream, it also increases in the steam drum and bubbles deflate, leading to a reduction of the level. Shrink and swell in the steam drum is therefore at the heart of coupling between vaporizer and superheater, thus 
increasing the complexity of the level control design, as well as the other control loops.

\subsection{Summary}

An important number of studies have been dedicated to recir culation. Table 1 sums up the control methods proposed by the quoted studies and the conclusions that are drawn.

\section{Control Systems for the once-through operation mode}

The once through architecture is the simplest of all, and therefore the cheapest option for the solar field. On the other hand, less controllable parameters are available to handle the disturbances and to ensure outlet steam quality. Due to the absence of phase separation and recirculation, there is also a larger coupling between disturbances in the preheating and vaporization section and the steam conditions in the superheating section. As previously mentioned, other issues are also the safety and dur ability of the absorber tubes. Prediction of the transition between saturated steam and superheated steam is indeed difficult, which makes the handling of the superheating process challenging.

Studies with the once through operation mode were also car ried out within the DISS project, around the experimental loop in Almeria. Valenzuela et al. $[29,30]$ propose a structure including a feedforward control loop for the outlet temperature control. Fig. 17 below shows the diagram of the DISS loop in once through mode.

The block diagram of the control system proposed for the loop is illustrated in Fig. 18 below. The control loops are detailed in the following subsections.

\subsection{Outlet steam pressure and feedwater valve pressure drop control loops}

As for the recirculation operation mode, the valve at the solar field inlet holds a specific pressure drop that is maintained con stant by the feed pump. The effect of having a constant pressure drop is that the relation between the valve aperture and the flow rate is linear, so that the valve aperture control loop is more effective.

Although the steam is theoretically dry at the superheater outlet, the final water/steam separator exists so that two phase flow can be handled in off design operating conditions. The pressure is regulated by the valve control on the outlet flow line to the turbine.

Those two control loops work with simple feedback and PI control, as presented for the recirculation concept. The controller parameters are computed with the same model approximation methods.

\subsection{Feedforward control structure for the outlet steam temperature}

The outlet steam temperature control is actually made up of two control systems. One uses the control of the first collector feedwater valve, the other one the control of the cooling water injection valve at the inlet of the last collector.

\subsubsection{Feedwater valve control}

The feedwater valve control system that is proposed by the authors is a cascade control loop using an outer master loop and an inner slave loop.

The master loop uses a feedforward controller to compute the inlet mass flow necessary to maintain the desired outlet steam temperature, using current irradiation and flow conditions. In parallel, a PI controller adjusts this mass flow using feedback from

Table 1

Summary of the proposed control systems for the recirculation operation mode.

\begin{tabular}{|c|c|c|c|c|c|c|c|}
\hline & $\begin{array}{c}\text { Vaporizer control } \\
\text { method - controller } \\
\text { type }\end{array}$ & $\begin{array}{c}\text { Controller } \\
\text { parametrization } \\
\text { method }\end{array}$ & $\begin{array}{l}\text { Separator control } \\
\text { method }\end{array}$ & $\begin{array}{c}\text { Controller } \\
\text { parametrization } \\
\text { method }\end{array}$ & $\begin{array}{l}\text { Superheater control } \\
\text { method }\end{array}$ & $\begin{array}{c}\text { Controller } \\
\text { parametrization } \\
\text { method }\end{array}$ & Study key points \\
\hline \multirow[b]{2}{*}{$\begin{array}{l}\text { Valenzuela } \\
\text { et al. [17] }\end{array}$} & $\begin{array}{c}\text { Constant recirculation } \\
\text { flow with recirculation } \\
\text { pump control - PI } \\
\text { feedback }\end{array}$ & \multirow{2}{*}{$\begin{array}{l}\text { Process model } \\
\text { approximation with } \\
\text { open-loop reaction } \\
\text { curve } \\
+ \\
+ \\
\text { Empirical tuning } \\
\text { rules and stability } \\
\text { margin }\end{array}$} & \multirow[b]{2}{*}{$\begin{array}{l}\text { Constant level with } \\
\text { feedwater valve } \\
\text { aperture control - PI } \\
\text { and feedback }\end{array}$} & \multirow{2}{*}{$\begin{array}{l}\text { Process model } \\
\text { approximation with } \\
\text { open-loop reaction } \\
\text { curve } \\
+ \\
\text { Empirical tuning rules } \\
\text { and stability margin }\end{array}$} & $\begin{array}{c}\text { Constant outlet } \\
\text { temperature with } \\
\text { injection flow rate } \\
\text { (valve aperture) control } \\
\text { - PI and feedback }\end{array}$ & \multirow{2}{*}{$\begin{array}{l}\text { Process model } \\
\text { approximation with } \\
\text { open-loop reaction } \\
\text { curve } \\
+ \\
+ \\
\text { Empirical tuning } \\
\text { rules and stability } \\
\text { margin }\end{array}$} & $\begin{array}{l}\text { Operation on } \\
\text { experimental } \\
\text { prototype }\end{array}$ \\
\hline & $\begin{array}{l}\text { Constant feedwater } \\
\text { valve pressure drop } \\
\text { with feedwater pump } \\
\text { control - PI feedback }\end{array}$ & & & & $\begin{array}{l}\text { Constant outlet } \\
\text { pressure with valve } \\
\text { aperture control - PI } \\
\text { and feedback }\end{array}$ & & $\begin{array}{c}\text { under clear sky and } \\
\text { mildly transient } \\
\text { irradiation }\end{array}$ \\
\hline \multirow{3}{*}{$\begin{array}{c}\text { Eck and } \\
\text { Hirsch }[21]\end{array}$} & \multirow{3}{*}{$\begin{array}{l}\text { Constant separator } \\
\text { level and steam } \\
\text { production with } \\
\text { feedwater control }\end{array}$} & & $\begin{array}{c}\text { Simple PI and } \\
\text { feedback on level - } \\
\text { Feedwater control }\end{array}$ & \multirow{3}{*}{$\begin{array}{c}\begin{array}{c}\text { Process model } \\
\text { approximation }\end{array} \\
+ \\
\text { "Manual" configuration } \\
\text { with objective on } \\
\text { overshoot and damping. } \\
\text { Use of adaptive } \\
\text { parametrization }\end{array}$} & $\begin{array}{l}\text { Injection flow rate: } \\
\text { Constant outlet } \\
\text { temperature - PI and } \\
\text { feedback }\end{array}$ & \multirow{3}{*}{$\begin{array}{c}\text { Use of a linearized } \\
\text { model (transfer } \\
\text { function) } \\
+ \\
\text { Adaptive } \\
\text { parametrization }\end{array}$} & \multirow{3}{*}{$\begin{array}{l}\text { Best vaporizer control } \\
\text { achieved with mix of } \\
\text { separator level and } \\
\text { steam production } \\
\text { feedback control } \\
\\
\text { Temperature control } \\
\text { more efficient if } \\
\text { includes full real-time } \\
\text { measurements with } \\
\text { feedforward }\end{array}$} \\
\hline & & & $\begin{array}{l}\text { Idem }+ \text { feedback on } \\
\text { superheater flow rate }\end{array}$ & & & & \\
\hline & & & $\begin{array}{l}\text { Idem + superheater } \\
\text { flow rate computation } \\
\text { with DNI } \\
\text { measurement and } \\
\text { energy balance } \\
\text { (feedforward) }\end{array}$ & & $\begin{array}{l}\text { Feedforward with real- } \\
\text { time measurements }\end{array}$ & & \\
\hline
\end{tabular}




\begin{tabular}{|c|c|c|c|c|c|c|c|}
\hline $\begin{array}{l}\text { Koch et al. } \\
\text { [19] }\end{array}$ & Out of scope & & Out of scope & & $\begin{array}{c}\text { Multirow control. } \\
\text { Difference-to-average } \\
\text { temperature control } \\
\text { with outlet valves (one } \\
\text { for each row) - PI and } \\
\text { feedback }\end{array}$ & $\begin{array}{c}\text { Single row linearized } \\
\text { model and matrix } \\
\text { mapping for } \\
\text { multirow model } \\
+ \\
\text { Row and flow- } \\
\text { dependant adaptive } \\
\text { parametrization }\end{array}$ & $\begin{array}{l}\text { In presence of } \\
\text { asymmetric irradiation } \\
\text { transients, overall } \\
\text { control is more } \\
\text { efficient if includes } \\
\text { row-wise flow control }\end{array}$ \\
\hline $\begin{array}{r}\text { Valenzuela } \\
\text { et al. [25] }\end{array}$ & Out of scope & & $\begin{array}{c}\text { Constant level with } \\
\text { feedwater valve - } \\
\text { feedback and dead- } \\
\text { time compensation } \\
\text { with modified Smith } \\
\text { predictors }\end{array}$ & $\begin{array}{l}\text { Specific to the used } \\
\text { predictors, see } \\
\text { references [25-27] }\end{array}$ & Out of scope & & $\begin{array}{l}\text { If tight separator level } \\
\text { control is necessary } \\
\text { (small design), } \\
\text { predictors are } \\
\text { necessary. }\end{array}$ \\
\hline $\begin{array}{l}\text { Birnbaum } \\
\text { et al. [16] }\end{array}$ & No information & & No information & & $\begin{array}{l}\text { Outlet temperature } \\
\text { setpoint with cooling } \\
\text { injection control } \\
\text { - } \\
\text { PI and feedback on } \\
\text { outlet and middle } \\
\text { superheater } \\
\text { temperature }\end{array}$ & Similar to [19] & $\begin{array}{c}\text { Temperature } \\
\text { deviations beyond } \\
\text { standards values in the } \\
\text { presence of irradiation } \\
\text { transients with } \\
\text { disadvantageous } \\
\text { dynamics }\end{array}$ \\
\hline \multirow{2}{*}{$\begin{array}{c}\text { Dominguez } \\
\text { et al. [23] }\end{array}$} & $\begin{array}{l}\text { Feedforward with DNI } \\
\text { "measurement"- } \\
\text { feedwater valve control }\end{array}$ & & \multirow{2}{*}{ Out of scope } & & $\begin{array}{c}\text { Outlet temperature } \\
\text { setpoint with vaporizer } \\
\text { control }\end{array}$ & & \multirow{2}{*}{$\begin{array}{c}\text { Feedwater valve } \\
\text { control more efficient } \\
\text { than enthalpy control } \\
\text { Enthalpy control } \\
\text { potentially interesting } \\
\text { for reducing steam } \\
\text { production drop if } \\
\text { DNI disturbance }\end{array}$} \\
\hline & $\begin{array}{c}\text { Feedforward with DNI } \\
\text { "measurement"- inlet } \\
\text { enthalpy control }\end{array}$ & & & & See vaporizer & & \\
\hline \multirow[t]{2}{*}{$\begin{array}{c}\text { Eck and } \\
\text { Steinmann }[24]\end{array}$} & $\begin{array}{c}\text { Outlet enthalpy } \\
\text { setpoint with feedwater } \\
\text { pump control } \\
- \\
\text { PI feedback }+ \\
\text { Feedforward with DNI } \\
\text { "measurement" }\end{array}$ & \multirow[t]{2}{*}{ No details } & \multirow[t]{2}{*}{ Out of scope } & & $\begin{array}{c}\text { Outlet temperature } \\
\text { setpoint } \\
\text { - } \\
\text { PI and feedback + } \\
\text { Feedforward with real- } \\
\text { time measurements }\end{array}$ & \multirow[t]{2}{*}{ No details } & \multirow[t]{2}{*}{$\begin{array}{l}\text { The control system is } \\
\text { found to be } \\
\text { satisfactory, but no } \\
\text { details. Study focuses } \\
\text { rather on injection }\end{array}$} \\
\hline & $\begin{array}{l}\text { Constant recirculation } \\
\text { ratio with recirculation } \\
\text { pump control - PI } \\
\text { feedback }\end{array}$ & & & & $\begin{array}{c}\text { Constant outlet } \\
\text { pressure with valve } \\
- \\
\text { PI and feedback }\end{array}$ & & \\
\hline
\end{tabular}

the actual outlet temperature. The inlet mass flow is the sum of both signals and is used as the setpoint of the inner control loop. This slave loop uses feedback and a PI controller to control the feedwater valve aperture to reach the required mass flow. The structure is pictured in Fig. 19.

The PI control part of the master loop and the slave loop are studied in open loop mode to determine a process model for each of them with, the process reaction method. With these models, PI parameters are computed. The fitted model and parameters are summed up in Fig. 20.

Computation of the feedforward output $m_{f f}$ is done through an energy balance on the overall collector:

$\left(m_{\text {in }}+m_{\text {inj }}\right) h_{\text {out }} \quad\left(m_{\text {in }} h_{\text {in }}+m_{\text {inj }} h_{\text {inj }}\right)=\eta_{\text {loop }} A_{\text {col }} L_{\text {loop }} E \quad U_{l} S_{\text {abs }}\left(T_{a v} \quad T_{\text {amb }}\right)$
The parameters of the equation are computed with methods and approximation summed up in Table 2.

With these parameters and methods, $m_{f f}$ can be computed. The signal from the feedforward controller is therefore supposed to be the total injected flow rate in order to reach the desired output temperature, the parallel signal given by the outlet temperature feedback loop being the adjustement.

The work of Eck and Steinmann [24] proposes a similar control loop for the outlet temperature control, but only the feedwater valve is available as an actuator in the model. There is no injection cooling. The aperture valve is controlled by the summed up signals of a PI feedback on the outlet temperature and a feedforward controller. The structure is shown in Fig. 21. 


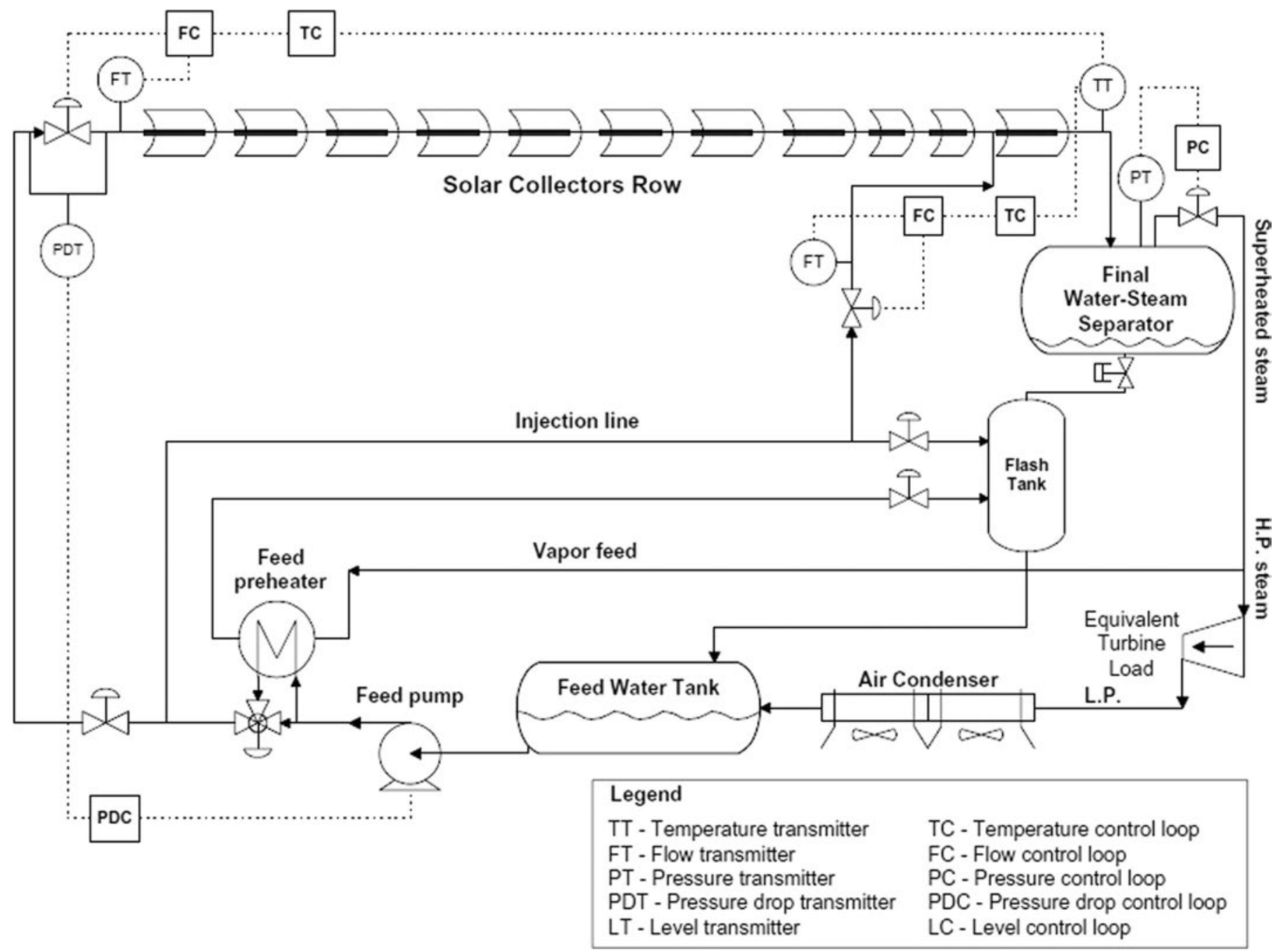

Fig. 17. DISS loop diagram, with once-through configuration, reprinted from [30].

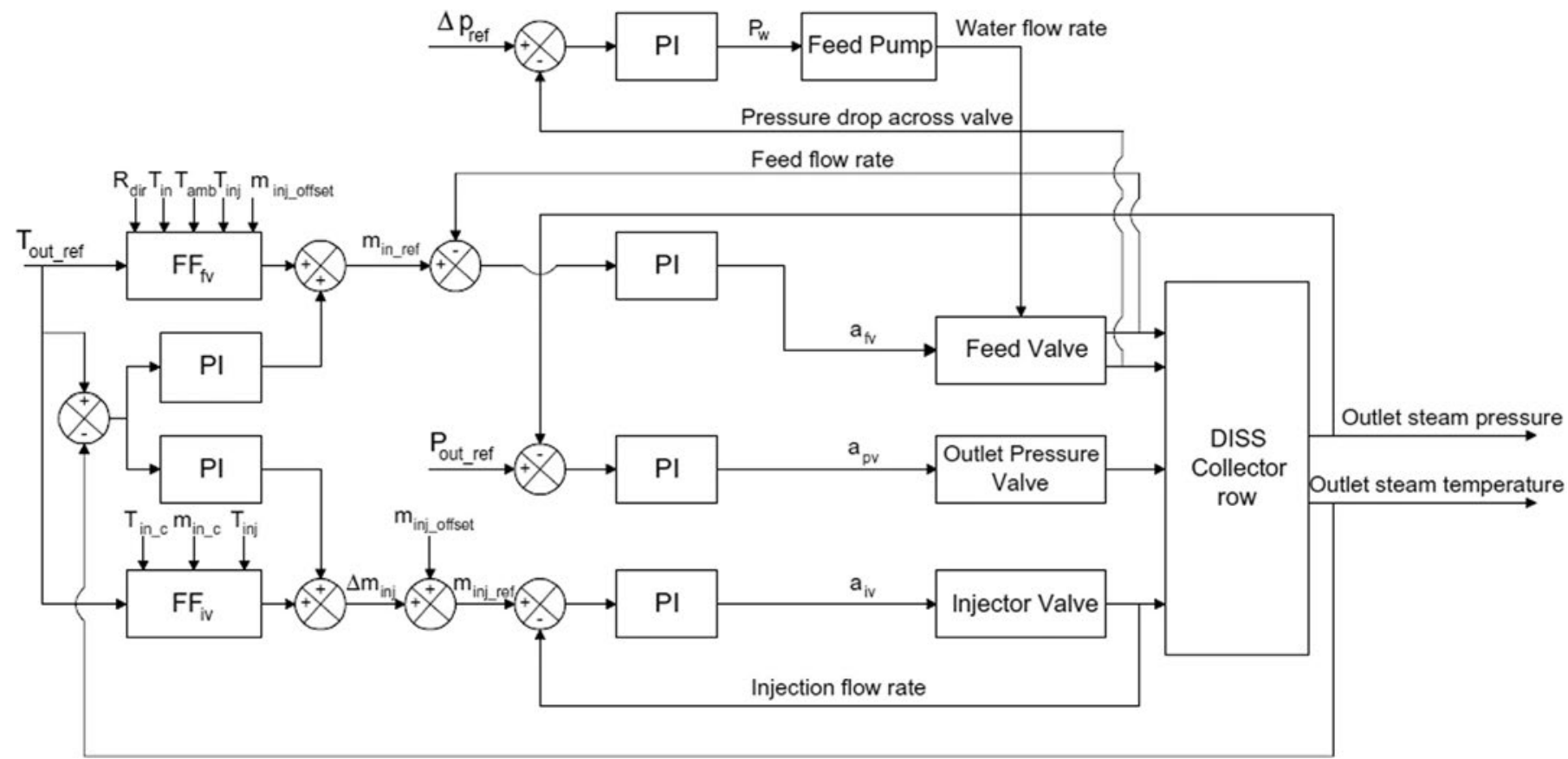

Fig. 18. Block diagram of the overall control system, reprinted from [30]. 


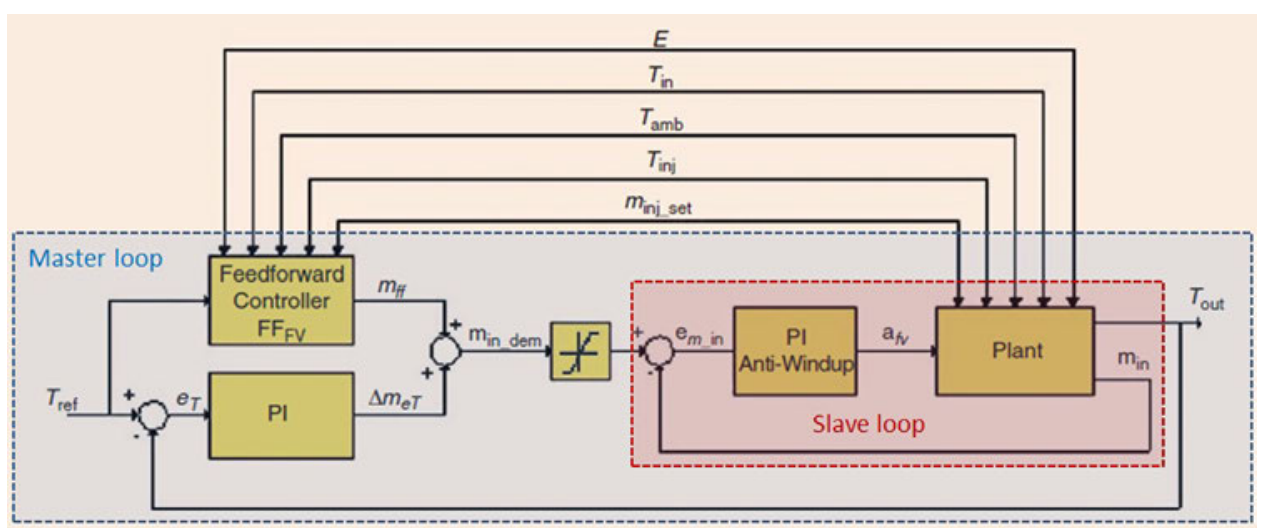

Fig. 19. Proposed feedwater valve control structure for the once-through mode, reprinted from [47].

\subsubsection{Injection cooling valve control}

Valenzuela et al. [29] mention that experiments with the injection valve have shown non linearities with its behavior. Its proposed cascade control structure, as for the feedwater control system, compensates them. The structure is shown in Fig. 22, extracted from [47].

This system uses a nominal injection flow rate that is manually dictated. The signal is corrected with the outer master loop output, which is the sum of two correction flow rates: the feedforward controller, which computes the correction injection flow rate $\Delta m_{f f}$ iv with current flow conditions, and the PI controller output $\Delta m_{e T}$ based on outlet temperature feedback. The inner slave loop uses this sum $\Delta m_{i n j}$ as the correction of the nominal injection flow rate $m_{\text {inj set }}$. The final input is then corrected by the injected mass flow feedback. The nominal flow rate $m_{i n j}$ set is also used in the feedwater valve control system, as seen in the previous section. The PI output of the slave loop is the valve aperture $a_{i v}$.

An energy balance on the last collector is used to compute the steady state injection mass flow, as it is done on the overall col lector for the feedwater valve control system (see previous sec tion). Using the energy balance, water and steam tables, and a set of input data, a regression analysis is carried out to identify the parameters of a multiple regression model:

$\Delta m_{f f \_i v}=c_{1} \Delta T_{i n_{-} c}+c_{2} \Delta m_{i n_{-} c}+c_{3} T_{r e f}+c_{4} T_{i n f}+c_{5}$

\subsection{Conclusions and perspective for once through mode}

Relatively few studies with the once through operation mode have been carried out so far. However, it remains potentially interesting for the cost reduction of the DSG process. That is why further investigations, including on more advanced control sys tems, are currently carried out at the Almeria platform with the ongoing DUKE project $[31,32]$.

\section{Control systems for the injection operation mode}

At the beginning of the DISS project, it was expected that the controllability of the injection operation mode would be better [14]. However, as of today, it remains the least studied operation mode, whether experimentally or numerically.

As for the once through operation mode, pre heating, vapor ization and superheating take place in the same absorber line. Knowledge of the transition regions is therefore also difficult, and the control systems design requires the assumptions that flow energy states are known at the injection positions.

The work of Eck and Eberl [33] presents the study of the per formance of two control systems, one using an adaptive PI controller, and the other one being Internal Model Control. Their study is explained below, including mentions of the original works from which models are derived. As few details are presented for the vaporizer section in the original article, only the description of the superheating section is proposed.

\subsection{Superheater modeling}

As it is mentioned in the work of Eck and Geskes [34], several models for the superheater were studied in the past, and it was found that the best model was a variant of the Marsik and Fortova model, in the form of transfer functions between the influence parameters.

Each section of the superheater comprises a collector and an injection unit. The transfer function between outlet temperature and injection mass flux is derived below. Subscript $a$ is the outlet state, $e$ the inlet state and $i$ the injection state:

$$
\tilde{G}(s)=\frac{\Delta T_{a}}{\Delta M_{i}} f \frac{c+0.2 s}{s(1+d s)}\left[a \frac{a}{(1+b s)^{n}} e^{-T_{t} s}\right]+\frac{a K_{M i}}{(1+b s)^{n}} e^{-T_{t} s}
$$

The parameters $a$ to $f$ and $T_{t}$ are described in [34]. The transfer functions between other relevant parameters (mass flux, tem peratures and irradiance) are also described in this work. The term $\frac{a}{(1+b s)^{n}} e^{-T_{t} s}$ is the transfer function from outlet temperature to inlet temperature $\frac{\Delta T_{a}}{\Delta T_{e}}$. The term $K_{M i}$ is the transfer function of the injection mass flux to the inlet temperature:

$K_{M i}=\frac{\Delta T_{e}}{\Delta M_{i}}=\frac{M_{e 0}\left(h_{i} \quad h_{e 0}\right)}{c_{e}\left(M_{e 0}+M_{i}\right)^{2}}$

\subsection{Superheater control system}

\subsubsection{Adaptive PI control}

The authors propose a control system relying on a PI controller with adaptive parameters. Indeed, they highlight the fact that fixed PI gain and reset time cannot be the optimum for all working condi tions. An optimization procedure using a controller effectiveness criterion is described to map the controller gain and reset time as a function of collector working conditions. Fig. 23 illustrates the need for adaptive PI parameters, it shows the optimized gain and reset time as a function of collector mass flux and specific enthalpy.

As a result of the optimization procedure, PI controller para meters are known for each state of the system. Parameters need now to be adapted during live operation of the system. To do so, the authors use the design procedure proposed by Astrom and which they described in the study. It uses the $G(s)$ process transfer function, and the transfer function in openloop with the PI 
PI Parameters

Feed pump

Outlet steam pressure

Outlet steam

temperature control via injector valve $\left(G_{1}\right.$ master loop, $G_{2}$ slave loop)

\section{Outlet steam}

temperature control via feed valve $\left(G_{1}\right.$ master loop, $G_{2}$ slave loop)

$$
G(s)=\frac{0.1375}{s^{2}+1.322 s+0.3329}
$$

$1.1 \% / \mathrm{bar}$

$G(s)=\frac{-4.54310^{-3} s-5.05 \cdot 10^{-5}}{s^{2}+4.976 \cdot 10^{-2} s+9.693 \cdot 10^{-5}}$

$G_{1}(s)=\frac{-a}{s+b} e^{-c s}$

$-0.0015 \mathrm{~kg} / \mathrm{s} /{ }^{\circ} \mathrm{C}$

where $a \in[3.12,8.13], b \in\left[5 \cdot 10^{-3}, 6.6 \cdot 10^{-3}\right]$ and $c \in[70,100]$

$$
\begin{aligned}
G_{2}(s) & =\frac{-3.2 \cdot 10^{-4}}{s+0.2} \\
G_{1}(s) & =\frac{-a}{s+b} e^{-c s}
\end{aligned}
$$$$
-500 \% / \mathrm{kg} / \mathrm{s}
$$$$
-8 \cdot 10^{-5} \mathrm{~kg} / \mathrm{s} /{ }^{\circ} \mathrm{C}
$$

where $a \in[1.365,2.526], b \in\left[1.8 \cdot 10^{-3}, 9.6 \cdot 10^{-4}\right]$ and $c \in[395,750]$

$$
G_{2}(s)=\frac{3 \cdot 10^{-2}}{s+0.1}
$$

\begin{tabular}{|c|c|c|}
\hline $\boldsymbol{m}_{i n}$ & Inlet flow rate & The feedforward controller output $\boldsymbol{m}_{f f}$ \\
\hline$m_{i n j}$ & Cooling flow rate & $\begin{array}{l}\text { Replaced by the manually fixed nominal flow } \\
\text { rate } m_{i n j} \text { set }\end{array}$ \\
\hline$h_{i n}$ & Inlet enthalpy & $\begin{array}{l}\text { Computed with a polynomial function to the } \\
\text { inlet temperature } T_{\text {in }}\end{array}$ \\
\hline$h_{\text {inj }}$ & $\begin{array}{l}\text { Cooling water } \\
\text { enthalpy }\end{array}$ & $\begin{array}{l}\text { Computed with a polynomial function to the } \\
\text { cooling water temperature } T_{i n j}\end{array}$ \\
\hline$h_{\text {out }}$ & Outlet enthalpy & $\begin{array}{l}\text { Computed with a polynomial function to the } \\
\text { reference temperature } T_{\text {ref }}\end{array}$ \\
\hline$\eta_{\text {loop }}$ & $\begin{array}{l}\text { Overall collector } \\
\text { efficiency }\end{array}$ & Estimated from experimental data \\
\hline$A_{\text {col }}$ & Collector aperture & \\
\hline$L_{\text {loop }}$ & Collector length & \\
\hline E & Irradiation & \\
\hline$U_{l}$ & $\begin{array}{l}\text { Thermal loss } \\
\text { coefficient }\end{array}$ & $\begin{array}{l}\text { Approximated with a polynomial to the tem- } \\
\text { perature difference } T_{a v}-T_{a m b}\end{array}$ \\
\hline$S_{a b s}$ & Absorber tube surface & \\
\hline$T_{a v}$ & $\begin{array}{l}\text { Fluid average } \\
\text { temperature }\end{array}$ & \\
\hline$T_{a m b}$ & Ambient temperature & \\
\hline
\end{tabular}

Fig. 20. Feedwater valve control loop parameters and models, reprinted from [47].

Table 2

Terms and computation methods for the feedforward controller output.

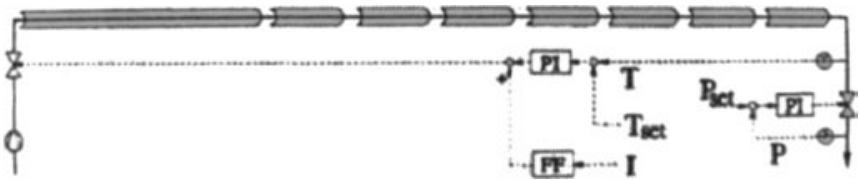

Fig. 21. Eck and Steinmann once-through model control system, reprinted from [24].

controller:

$G_{0}(s)=K\left(1+\frac{1}{T s}\right) \tilde{G}(s)$

Eq. (33) can be translated into a phase and an absolute value relations, with which controller parameters yield:

$T=\frac{1}{\omega_{d}} \tan \left(\varphi_{0} \quad \varphi_{G}\right)$

$$
K=\sin \left(\varphi_{0} \quad \varphi_{G}\right) \frac{\left|G_{0}\left(j \omega_{d}\right)\right|}{\left|\tilde{G}\left(j \omega_{d}\right)\right|}
$$

For every state of the transfer function $\tilde{G}(s)$ (that is to say for each frequency $\left.\omega_{d}\right)$, the corresponding open loop point $G_{0}\left(j \omega_{d}\right)$ is computed using Eqs. (34) and (35), and the optimized values of $K$ and $T$ (previously obtained from the optimization procedure). All the state points $G_{0}\left(j \omega_{d}\right)$ are then plotted on the Nyquist diagram (knowing the phase and gain). A points "cloud" on the Nyquist diagram is eventually obtained, representing the set of system states of the openloop. From these points, one of them, yielding a good compromise between all the states, is visually chosen as a reference point. Its phase and absolute value are then used for the online computation of $K$ and $T$ for every state of the process $G(s)$, again with Eqs. (34) and (35).

The advantage of this design procedure is that optimization of parameters $K$ and $T$ is run only once before live operation, and they are then adapted during operation with simple computations. For each state of the process, the knowledge of only point is necessary (to have $\omega_{d}, \varphi_{G}$ and $\left|\tilde{G}\left(j \omega_{d}\right)\right|$ ) to compute the adapted PI controller parameters.

\subsubsection{Internal Model Control}

An Internal Model Control (IMC) structure was also tested by the authors of the same study. The basic idea of IMC is to use an estimation of the process to design the controller. Fig. 24 below illustrates the structure.

$g(s)$ is the process to control, and $\tilde{g}(s)$ is its estimation. $d$ and $\hat{d}$ are the disturbance and the disturbance estimation. The block diagram can be formulated in other equivalent structures, pictured in Fig. 25.

From the conventional feedback diagram, it can be seen that applying an ICM design method consists in defining controller c. It is usually expressed as the product of the inverse of the estimated process model $\tilde{g}(s)$ invertible part $\tilde{g}_{-}$and a filter:

$c(s)=\frac{1}{\tilde{g}_{-}} f(s)$

The filter usually has the form below. $\lambda$ is a parameter and $n$ is the order, chosen so that $c(s)$ is proper (having a numerator order 


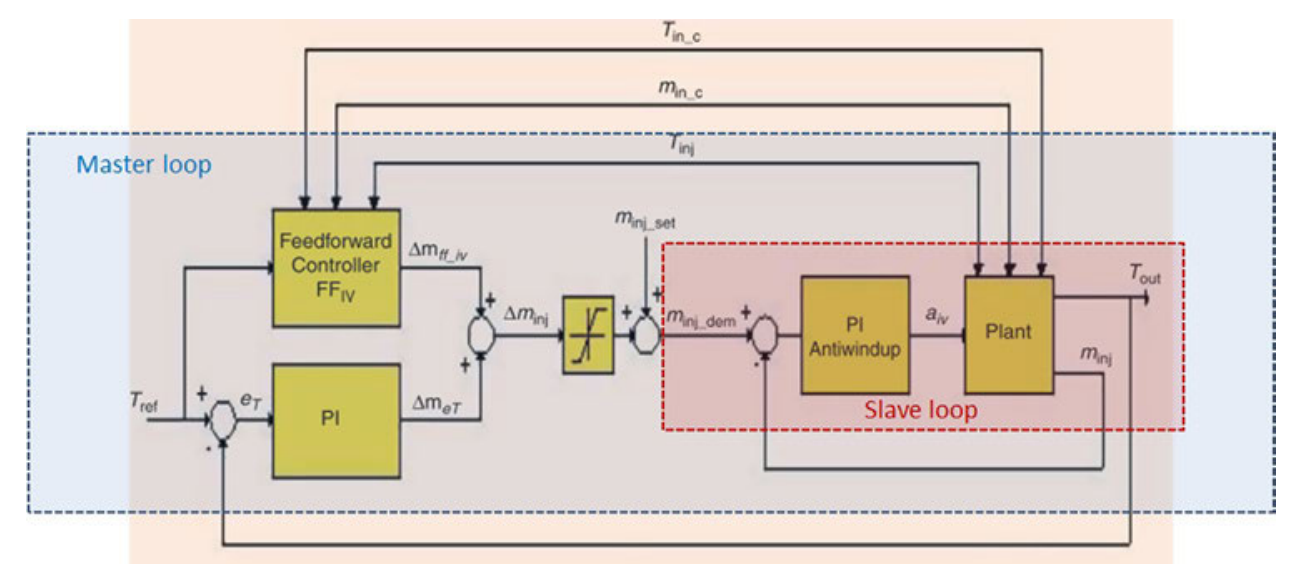

Fig. 22. Proposed injection valve control structure for the once-through mode, reprinted from [47].

a

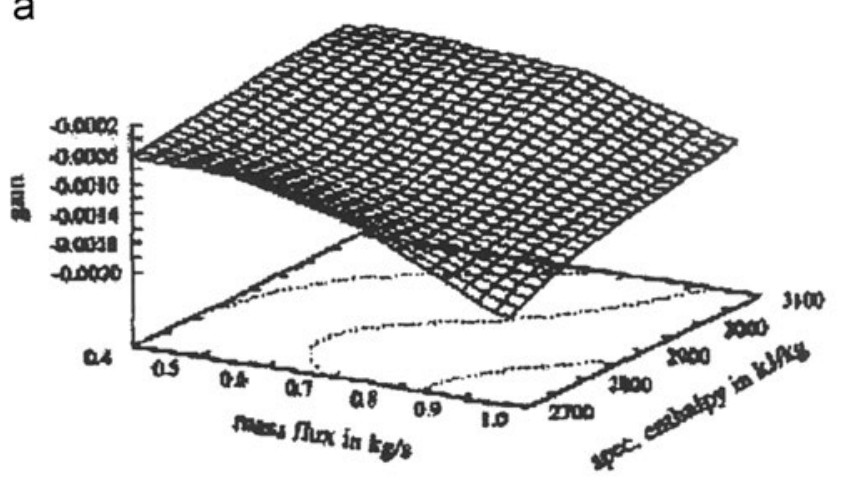

b

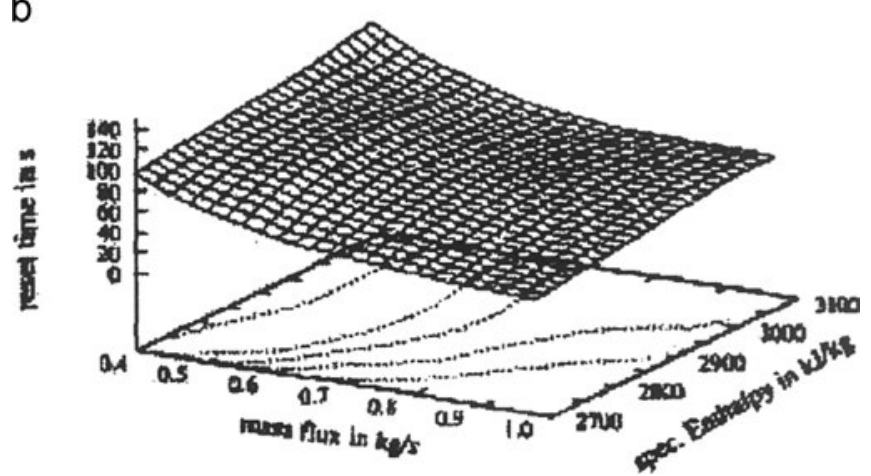

Fig. 23. Controller gain (a) and reset time (b) mapping with collector inlet mass flux and specific enthalpy, reprinted from [33].

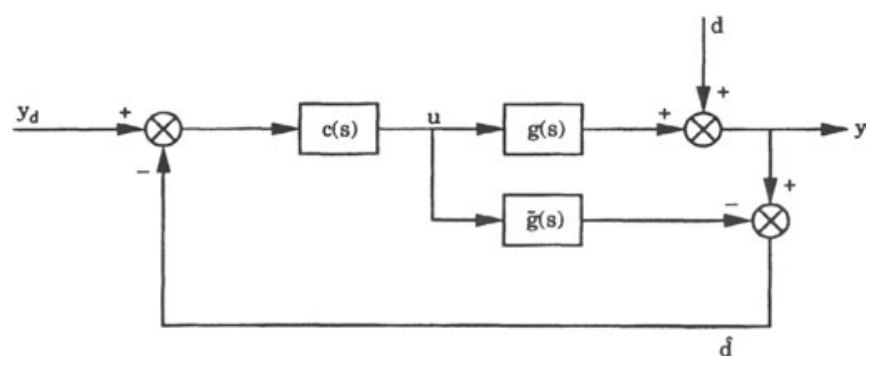

Fig. 24. IMC control structure, reprinted from [18].

less than the one of the denominator).

$f(s)=\frac{1}{(\lambda s+1)^{n}}$
For further details about IMC design, see reference [32], and see [30] for more details about the design of this specific IMC system.

\subsubsection{Performance of the control systems}

Simulations are carried out for the loop working with the IMC system designed as a first try, and the adaptive PI controller. The outlet temperature response for both systems is shown in Fig. 26.

As can be seen in Fig. 27 below, unacceptable oscillatory behavior of the actuating signal is found for the IMC system, while the adaptive PI control works well.

The IMC system was redesigned as a second iteration by modifying the model approximation $\sim g$. Fig. 28 shows that the outlet temperature settling time is increased and is worse than with the PI system:

It can be seen however, in Fig. 29, that the IMC signal is no longer oscillatory:

\subsection{Conclusion of the study of Eck and Eberl (1999)}

This work is among the first to study control systems applied to DSG in line focus collectors, even if it is with the injection mode. This architecture remains indeed today relatively poorly applied or studied.

Introducing the adaptive PI control design method, the authors demonstrate its usefulness showing that the controller parameters cannot be ideal for all working conditions. A relatively complex IMC design method is also proposed in the study. Simulations show that the adaptive PI control method has better performance than IMC, while being simpler to implement. It should be noted that this work, despite being included in a study of the injection architecture, focuses on the superheating section control system and therefore can be applied to any architecture. It is indeed similar for all operation modes since the control component essentially consists in injection cooling, or "desuperheating".

\subsection{Work of Eck and Steinmann (2000)}

The study of Eck and Steinmann [24] proposes a control system using the same adaptive PI control, and the addition of a feed forward component. Each of the injectors is given an enthalpy setpoint, and the injection flow rate signal is the sum of the PI corrected enthalpy feedback error and the one calculated by the feedforward controller using irradiation measurement. Fig. 30 shows the structure.

As shown in Fig. 31 below, the simulations of irradiance tran sients on this solar field with this ideal control system (plain line) show very good stability of the outlet temperature. Irradiance 

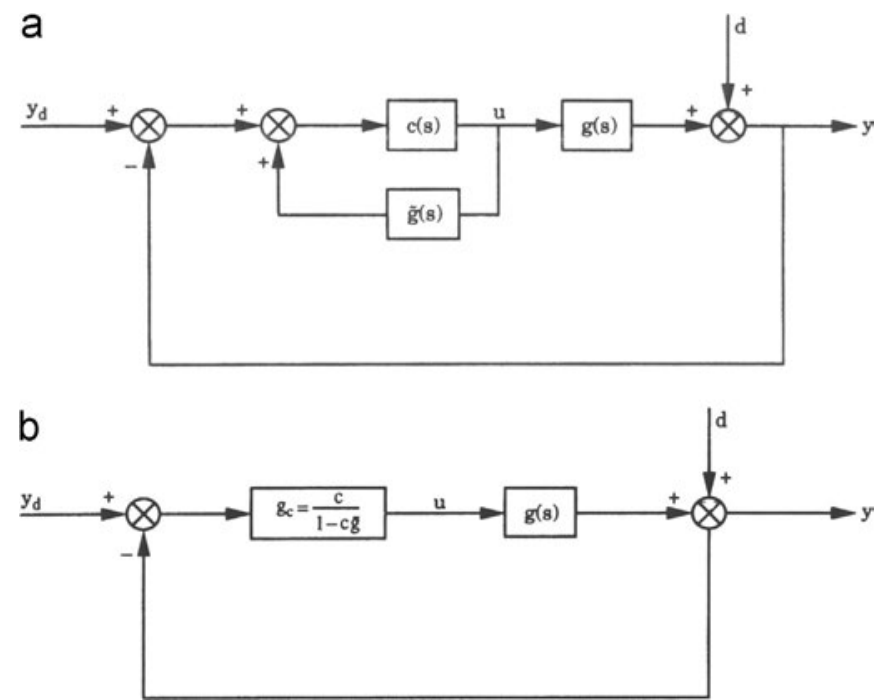

Fig. 25. Alternative block structures: inner loop (a) and conventional feedback control (b), reprinted from [18].

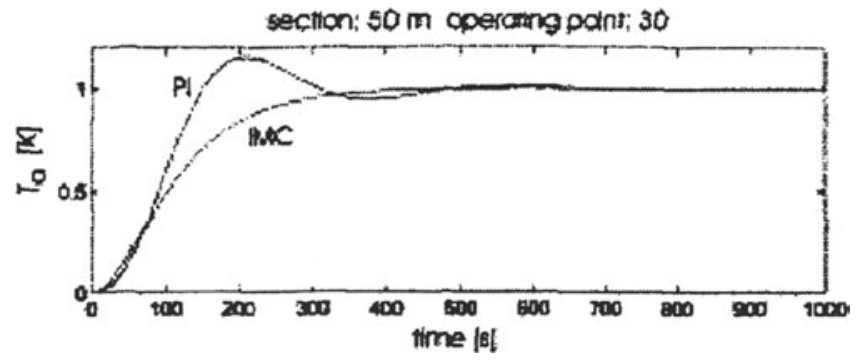

Fig. 26. Outlet temperature control with PI and IMC, reprinted from [33].

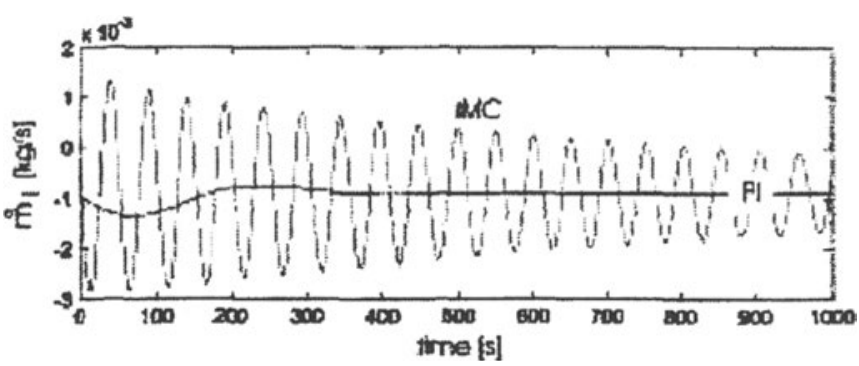

Fig. 27. Control systems actuating signal, reprinted from [33].

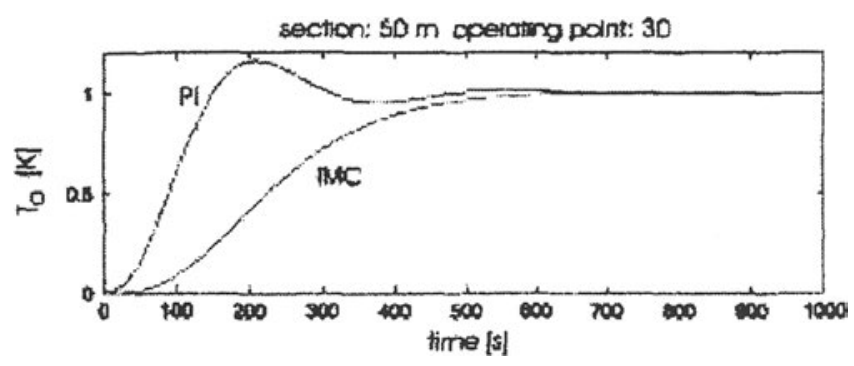

Fig. 28. Outlet temperature control after IMC redesign, reprinted from [33].

disturbance on each collector is well compensated by the corre sponding injected mass flow change.

However, a further study points out that the precision of the irradiation measure is crucial because it strongly affects the

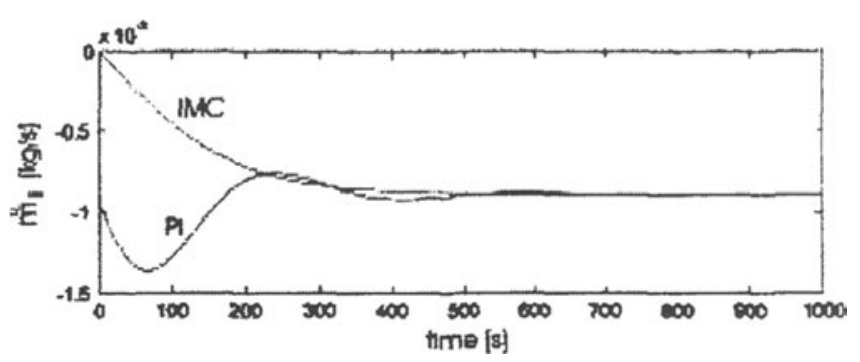

Fig. 29. Control systems actuating signal after IMC redesign, reprinted from [33].

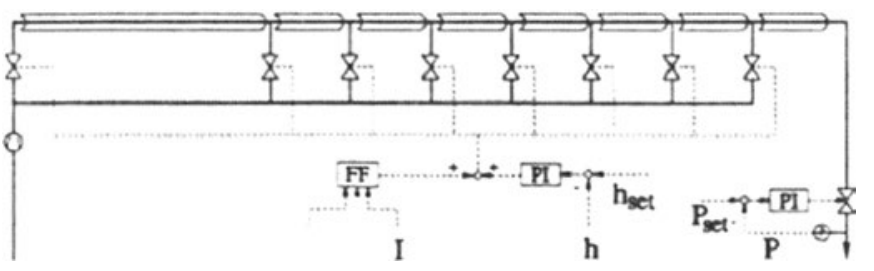

Fig. 30. Injection mode proposed control system, reprinted from [24].

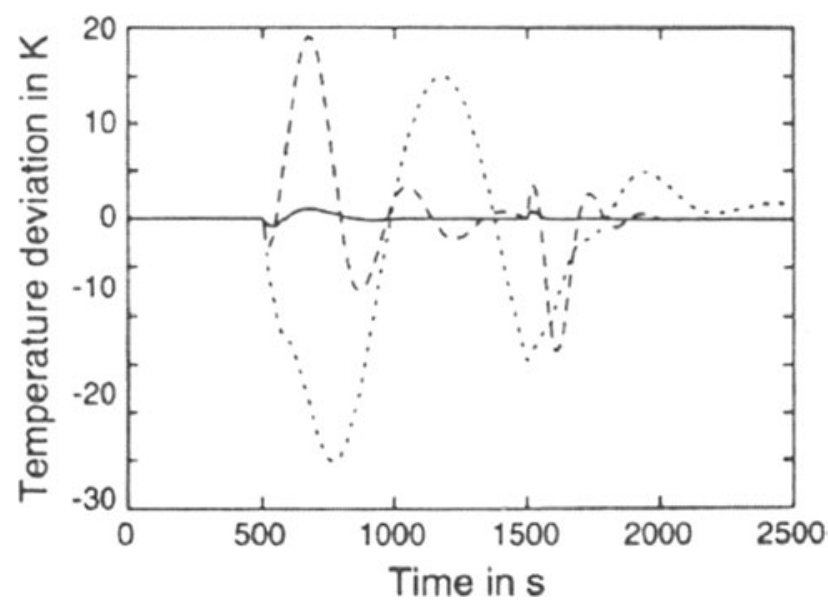

Fig. 31. Outlet temperature deviation after temporary shading of collectors, for once-through $\left(^{* * *}\right)$, recirculation (- - ), and injection (-), reprinted from [24].

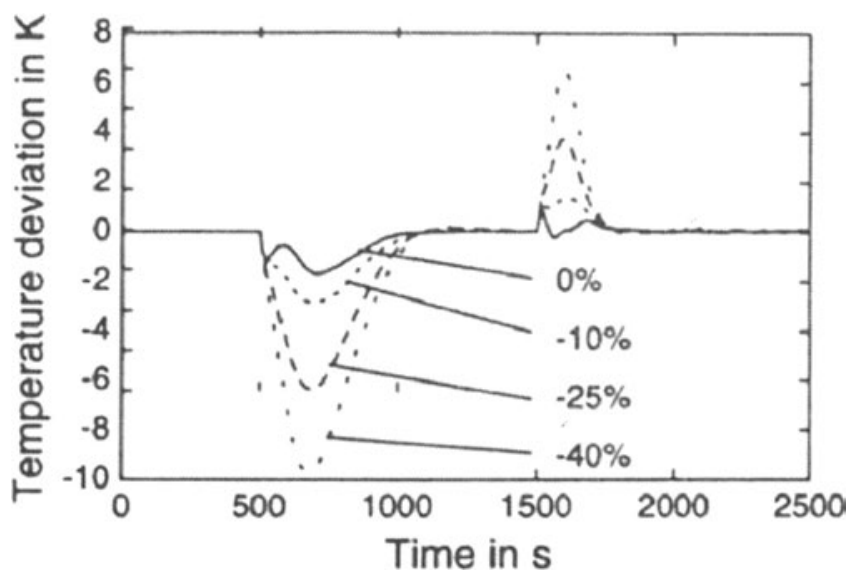

Fig. 32. Influence of DNI measurement error on the outlet temperature deviation, for a 3 injection points variant, reprinted from [24].

control performance. The influence of an irradiation measurement error on the outlet temperature deviation can be seen in Fig. 32 below. 


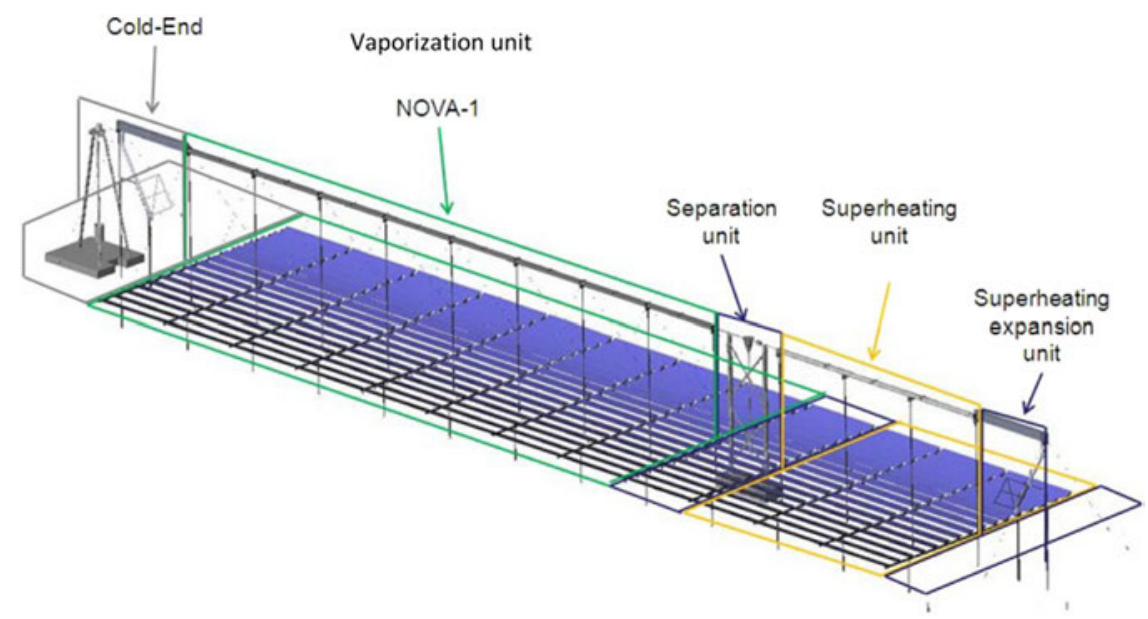

Fig. 33. The SUPERNOVA collector, by Novatec Biosol, reprinted from [38].

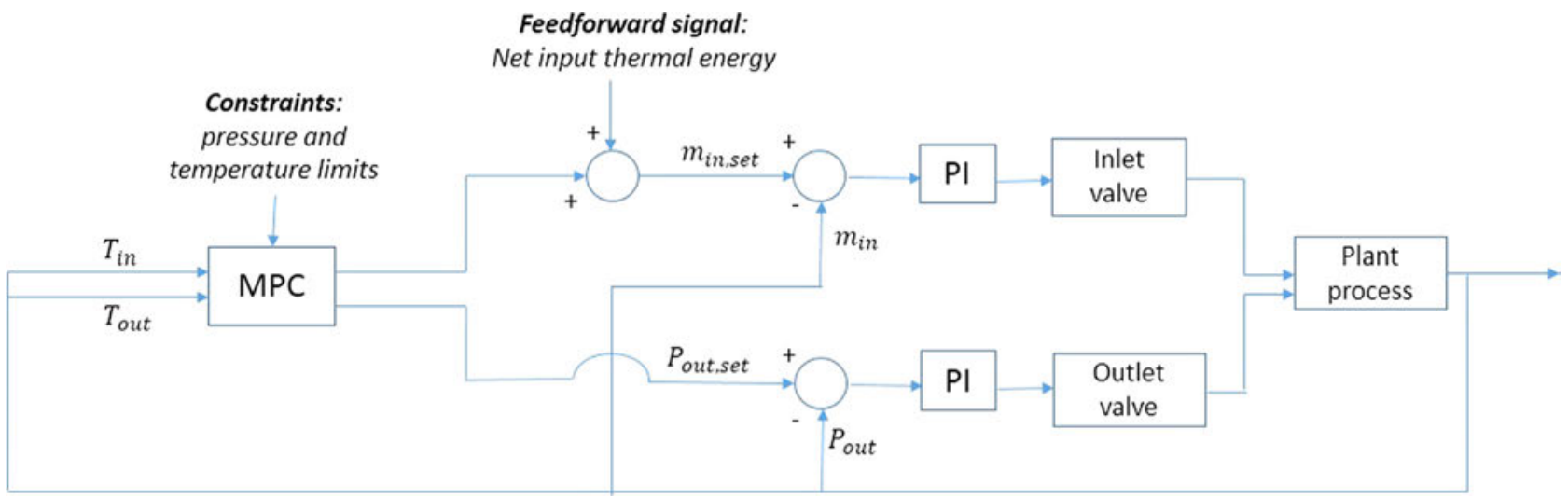

Fig. 34. SSG4 control scheme.

This shows that the good efficiency of the control system with feedforward relies on a precise local irradiation measurement, so that the advantage of the injection operation mode over the other ones is not lost. It is then safe to assume that applying that tech nology in an actual size plant, in which a large solar field would imply using several measurement devices, is relatively expensive.

\section{Results from experience on line-focus DSG plants in operation}

There are few commercial CSP plant using direct steam gen eration currently operating, and even fewer applied with a line focus technology. To our knowledge, at the time of this work, only four are connected to an electrical grid for actual production. Some data and basic technical information are available in literature, but very few knowledge about the control systems is published, as it is of course the property of the plants operators and developers. Nevertheless, it seems interesting to put control methods pro posed in literature (which are the results of simulation studies for the most) in the reference frame of what is actually applied today.

\subsection{The parabolic trough plant Thai Solar One}

The Thai Solar One (TSE 1) solar thermal power plant, devel oped by Solarlite, and located in Kanchanaburi, Thailand, is the first and only commercial plant to use DSG in a parabolic trough solar field. Its peak production capacity is $5 \mathrm{MW}$ electrical, and it has been operated since 2011. The solar field is operated in recirculation mode, with 12 evaporator loops and 7 superheater loops, and a central steam separator [35]. The plant is located in a region with a challenging climate for CSP, and a recent evaluation of the vaporizer performance was done recently by the DLR, in which some limited information is available about control strategy [36]. The mass flow is controlled in each loop with a valve at the inlet. The DNI is measured and used for computation of the mass flow setpoint, which is a feedforward control method. It is shown that flow stability is ensured for days with stable DNI and days with mildly transient DNI, but also that highly transient DNI leads to flow instability between parallel loops and local overheating incidents.

\subsection{The Fresnel plant Puerto Errado 1}

In 2009, the Fresnel linear plant Puerto Errado 1 (PE 1 ) started operation in Spain. The plant was developed by the former com pany Novatec Biosol (later Novatec Solar, and today Frenell) and use their NOVA 1 collector technology producing saturated steam [37]. After successful demonstration of operation, the SUPERNOVA collector was designed and built with the aim of using super heated steam up to $450{ }^{\circ} \mathrm{C}[38,39]$, and was integrated in PE I. Fig. 33 shows a diagram of the collector, on which a separation unit is visible, which indicates an operation in recirculation mode, or equivalent.

The outlet temperature control is done through focused area control (which is specific to Fresnel), steam mass control, and injection cooling control [40]. It is shown in the latter reference that good temperature stability is achieved even on days with 


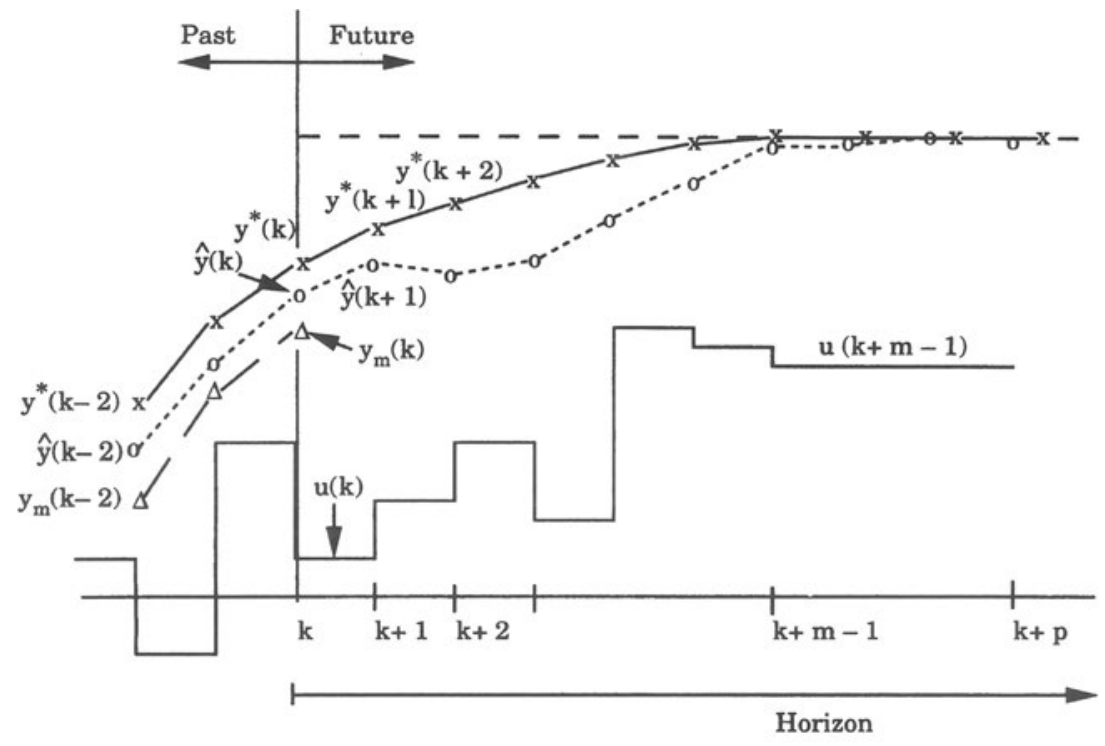

Example of elements in model predictive control: $x-x$ : reference trajectory, $y^{*} ; 0---o:$ predicted output, $\hat{y} ; \Delta--\Delta$ : measured output, $y_{m} ;-$ control action, $u$.

Fig. 35. Diagram of a MPC scheme main elements, reprinted from [18].

relatively high irradiation transients. As the authors mention that steam mass flow control through pressure variation is not adapted to large power plants using steam turbines, operation without mass flow control is tested as well. Results show good temperature stability for a day with good irradiation conditions.

The simulation study part of this referenced work mentions a control method for the cooling injection based on real time irra diation and collector efficiency measurement and energy balance. This is therefore a feedforward control method, with the addition of a feedback control component.

\subsection{The Fresnel plant Puerto Errado 2}

Following the proof of concept of generating superheated steam in Fresnel collector with Puerto Errado 1, Novatec Solar started operation of the 30 MWe plant Puerto Errado 2 in 2012. It is based on the SUPERNOVA collector, and located next to the PE 1 plant [41]. The control system is similar to the one of PE 1, with feedforward computation of the required mass flow for each row as a function of focused area, collector efficiency and available irradiation. The actuators are control valves located at the inlet of each row, and the control system is designed so that each row is as autonomous as possible.

\subsection{The CLFR (Compact Linear Fresnel Reflector) SSG4 collector}

The Compact Linear Fresnel Reflector is a concept of linear Fresnel collector originally proposed in the work of Mills and Morrison [42], and later used as the design basis of Areva Solar DSG plants [43]. This latter reference presents the SSG4 direct steam generation collector operated in once through mode with a two pass arrangement at the Kimberlina solar thermal plant. SSG4 can be used for delivering steam directly to a turbine or as a solar boost for industrial heat processes.

Described in [44], is a model predictive control method (MPC) for the collector. Outlet pressure and inlet mass flow rate are the control variables with their respective valves. The MPC provides the inlet flow rate and outlet pressure setpoints in an outer control loop, to inner control loops using feedback and PI controllers. The live irradiation measurement is used as a supplementary feedfor ward signal to compute the inlet flow rate setpoint. The overall control scheme is represented as a block diagram in Fig. 34.

The performance objective of the control system is to keep the steam conditions in the range of $+/ 20^{\circ} \mathrm{C}$ and $+/ 3$ bars from the setpoints. These objectives were met in a test campaign in 2010, according to [44]. No information about the gradients of the dynamics is given. This control method using MPC is also descri bed in a European patent [45].

Model Predictive Control is currently popular among engineers in the field of industrial process control, especially for the pro cesses showing difficult dynamics (large dead time, inverse response, instabilities, etc.) [18]. It is surely true for line focus CSP and the SSG4 collector presented in this section. However, as we could see in the previous sections, almost no study of line focus DSG systems (even only theoretical or numerical) proposes the use of such methods. This is probably due to the fact that engineers are trying to design systems with simple control methods, keeping in mind that plant operators should not have to go through specific and complex training in process control. The basic principle of MPC is to use the prediction of the future behavior of the process (i.e. the behavior including the full effect of the last control action) to compute the control action to be undertaken, so that the error between predicted behavior and the desired behavior (referred as "reference trajectory") over a certain time horizon is reduced toward correction. Fig. 35 shows an example of the main elements of a MPC scheme on a time plot. $y^{*}$ is the desired trajectory of the process output over a certain time horizon and $\hat{y}$ is the prediction of the process output over that same horizon. $y_{m}$ is the actual measured output of the process and $u$ is the control action com puted for the same time horizon.

\subsection{CNIM CLFR concept}

The CNIM company has developed a Fresnel collector using a recirculation architecture. The concept for a solar field that would use this collector and its control considerations are presented in reference [46]. The proposed system includes injection cooling in the superheater to control solar field outlet temperature, turbine 
inlet steam pressure control with the steam drum (including flashing when vaporizer flow gets small), and an auxiliary gas boiler between the superheater and the turbine to handle large DNI drops. No more details are available about the control system.

\section{Acknowledgments}

The authors acknowledge the financial support of the French Alternative Energies and Atomic Energy Commission.

\section{References}

[1] OECD/IEA. Technology roadmap concentrating solar thermal electricity; 2014

[2] OECD/IEA. Technology roadmap concentrating solar power; 2010.

[3] Goebel $\mathrm{O}$ and Hennecke K. Investigation of thermohydraulics in a parabolic trough absorber tube with DSG. In: Proceedings of the 8th international symposium on CSP technologies; 1996.

[4] May EK and Murphy L. Steam generation in line-focus solar collectors : a comparative assessment of thermal performance, operating stability, and cost issues. Technical Report, SERI/TR-632-1311; 1982

[5] Herbst O, Fechner A, Kohler W, Goebel O, Oberle B. Heat transfer behaviour of an absorber tube with direct steam generation by water injection. Convective Flow Boiling; 1995.

[6] Kohler W, Herbst O, and Kastner W. Thermal design of solar absorber tubes with direct steam generation. In: Proceedings of the 8th international symposium on CSP technologies; 1996.

[7] Zarza E, Valenzuela L, Leo J, Eck M, Weyers H, Eickhoff M. Direct steam generation in parabolic troughs : final results and conclusions of the DISS project. Energy 2004;29:635-44.

[8] Taylor P, Hirsch T, Feldhoff JF, Hennecke K, Pitz-paal R. Advancements in the field of direct steam generation in linear solar concentrators - a review. Heat Transf Eng 2013:37-41.

[9] Eck M, et al. The potential of direct steam generation in parabolic troughsresults of the German project DIVA. In: Proceedings of the 14th biennal CSP SolarPACES symposium; 2008.

[10] Feldhoff JF, Eck M, Benitez D, and Riffelmann K.-jürgen. Economic potential of solar thermal power plants with direct steam generation compared to HTF plants. In Proceedings of the ES2009 conference, 2009. p. 663-71.

[11] Feldhoff JF, et al. Comparative system analysis of direct steam generation and synthetic oil parabolic trough power plants with integrated thermal storage. Sol Energy 2012;86(1):520-30.

[12] Eck M, Zarza E, Eickhoff M, Rheinlander J, Valenzuela L. Applied research concerning the direct steam generation in parabolic troughs. Sol Energy 2003; $74: 341-51$.

[13] Odeh SD, Morrison GL, Behnia M. Modelling of parabolic trough direct steam generation solar collectors. Sol Energy 1998;62(6):395-406.

[14] Zarza E, Ajona J, Hennecke K. Project DISS-technological program on solar power plants with parabolic troughs and direct solar steam generation. Sola Engineering-ASME; 1997.

[15] International Electrotechnical Commission (IEC). Steam turbines-part 1: Specifications. IEC 60045-1; 1991

[16] Birnbaum J, et al. Steam temperature stability in a direct steam generation solar power plant. Sol Energy 2011;85:660-8.

[17] Valenzuela L, Zarza E, Berenguel M, Camacho EF. Control scheme for direct steam generation in parabolic troughs under recirculation operation mode. Sol Energy 2006;80:1-17.

[18] Ogunnaike BA, Ray W Harmon. Process dynamics, modeling, and control. Oxford University Press; 1994

[19] Koch S, Eck M, Hirsch T. Modelling and control of a solar-thermal parabolic trough DSG superheater with several parallel rows and central steam separation. In: Proceedings of the ES2007-Energy Sustainability; 2007. p. 1005-14.

[20] Marsik J, Fortova A. Eine neue einfache Methode der Berechnung von Ubergangsfunktionen eines Dampferhitzers. Automatisace 1958;6:188-90.
[21] Eck M, Hirsch T. Dynamics and control of parabolic trough collector loops with direct steam generation. Sol Energy 2007:81:268-79.

[22] Zarza E, Esther M, Gonza L, Caballero M, Rueda F. INDITEP : the first precommercial DSG solar power plant. Sol Energy 2006;80:1270-6.

[23] Domínguez LF, Klasing F, and Mercangöz M. Modeling and control of a linear fresnel collector system. In: Proceedings of the European control conference; 2014. p. $1042-48$

[24] Eck M and Steinmann W.-dieter. Dynamic behaviour of the direct steam generation in parabolic trough collectors: a simulation study. In: Proceedings of the 10th SolarPACES international symposium; solar thermal 2000; 2000. p. 101-6.

[25] Valenzuela L, Zarza E, and León J. Approaches for controlling the level in water/steam separators of a DSG solar field configured in recirculation mode. In: SolarPACES2006; 2006. p. 1-8.

[26] Matausek M, Micik A. A modified smith predictor for controlling a process with an integrator and long dead-time. IEEE Trans Autom Control 1996;41 (8):1199-203.

[27] Normey-rico JE, Camacho EF. Robust tuning of dead-time compensators for processes with an integrator and long dead-time. IEEE Trans Autom Control 1999;44(8):123-9.

[28] Watanabe K, Ito M. A process-model control for linear systems with delay. IEEE Trans Autom Control 1981:26(6):1261-9.

[29] Valenzuela L, Zarza E, Berenguel M, Camacho EF. Direct steam generation in solar boilers, using feedback to maintain conditions under uncontrollable solar radiations. IEEE Control Syst Mag 2004;29:15-29.

[30] Valenzuela L, Zarza E, Berenguel M, Camacho EF. Control concepts for direct steam generation in parabolic troughs. Sol Energy 2005;78:301-11.

[31] Feldhoff JF, et al. Concept comparison and test facility design for the analysis of direct steam generation in once-through mode. In: SolarPACES2012; 2012.

[32] Feldhoff JF, et al. Status and first results of the DUKE project - component qualification of new receivers and collectors. Energy Procedia 2014:49:1766-76.

[33] Eck M, Eberl M. Controller design for injection mode driven direct solar steam generating parabolic trough collectors. In: Proceedings of the 1999 solar world congress; 1999. p. 247-57.

[34] Eck M, Geskes P. Experimental Investigations on the dynamic fluid behavior in horizontal absorber tubes with direct steam generation.pdf. J de Phys 1999;9:129-34.

[35] Krüger D, et al. Experiences with direct steam generation at the Kanchanaburi solar thermal power plant. In: SolarPACES2012; 2012

[36] Khenissi A, Krüger D, Hirsch T, Hennecke K. Return of experience on transient behavior at the DSG solar thermal power plant in Kanchanaburi, Thailand. In: SolarPACES2014, vol. 0; 2015

[37] Hautmann G, Selig M, and Mertins M. First European linear fresnel power plant in operation-operational experience \& outlooK. In: SolarPACES2009, vol. $1 ; 2008$.

[38] Selig M and Mertins M. From saturated to superheated direct solar steam generation - technical challenges and economical. In: SolarPACES2010; 2010.

[39] Morin G, Mertins M, Kirchberger J, and Selig M. Supernova - construction, control \& performance of steam superheating linear fresnel collector. In: SolarPACES2011. p. 1-6.

[40] Morin G, Kirchberger J, Lemmertz N, Mertins M. Operational results and simulation of a superheating Fresnel collector. In: SolarPACES2012; 2012.

[41] Mertins M, Link E, Tscheche M, Leuckel H. Experiences of operation of a $30 \mathrm{MW}$ solarthermal power station based on Fresnel collector technology. In: SolarPACES2012; 2012.

[42] Mills DR, Morrison GL. Compact linear fresnel reflector solar thermal powerplants. Sol Energy 2000;68(3):263-83.

[43] Conlon WM. Superheated steam from CLFR solar steam generators. In: SolarPACES2011; 2011.

[44] Tanner P, Rasmussen K, Johnson P, Hoermann A, and Cheng W. Control of solar steam generators. In: Proceedings of the ASME-POWER2011 conference; 2011.

[45] Tanner P and Rasmussen K. Method of controlling a direct solar steam generator and corresponding control system; 2013.

[46] Alliotte R. Superheated direct steam generation: alternative configuration for CLFR solar plants. In: SolarPACES2011; 2011.

[47] Loreto Valenzuela Gutiérrez. Control automático de plantas de generación directa de vapor con colectores solares cilindro-parabólicos. Edited by CIEMAT, Madrid; 2008. ISBN: 978-84-7834-581-6. 